\title{
新型樟脑磺胺基肜醚衍生物的合成及抗肿瘤活性研究
}

\author{
赵雨珣王芸芸张成龙徐徐王石发* \\ (南京林业大学林业资源高效加工利用协同创新中心＼cjkstart化学工程学院＼cjkstart南京 210037)
}

\begin{abstract}
摘要 利用药物设计中的活性拼接原理，以(+)-10-樟脑磺酸为原料, 经酰氯化、酰胺化和缩合反应, 设计合成了一系 列樟脑磺胺基弜醚类衍生物, 通过 ${ }^{1} \mathrm{H} N M R 、{ }^{13} \mathrm{C}$ NMR 和 HRMS 对其结构进行了表征. 采用噻唑蓝(MTT)法对目标化 合物对人肺腺癌细胞(A549)、人宫颈癌细胞(Hela)、人乳腺癌细胞(MCF-7)和人正常胚胎肝细胞(LO2)进行抗肿瘤活性 评价。结果表明, 大部分化合物显示出良好的抗肿瘤活性。其中, (+)-1-(7,7-二甲基-2-(芐氧基亚氨基)双环 [2.2.1]庚烷-1基)- $N$-(3-(三氟甲基)苯基)甲磺酰胺(4r)对三种细胞表现出最好的抗增值效果, $\mathrm{IC}_{50}$ 值分别为 $6.75 、 7.93$ 和 $4.51 \mu \mathrm{mol} \cdot \mathrm{L}^{-1}$. 采用流式细胞术检测细胞周期和调亡, Hoechst 染色观察细胞形态变化. 苂光探针 DCFH-DA 和 JC-1 分别用于检测细胞 内活性氧水平和线粒体膜电位. 初步机理研究表明, 化合物 $\mathbf{4 r}$ 可将 MCF-7 细胞阻滞在 G0/G1 期, 可诱导活性氧产生和 线粒体膜电位崩溃进而诱导细胞呈剂量依赖式调亡.
\end{abstract}

关键词＼cjkstart樟脑磺胺基肜醚；抗肿瘤活性; G0/G1 期阻滞; 调亡

\section{Synthesis of Novel Camphor Sulfamoxime Ether Derivatives and Its Application in Antitumor Activity}

\author{
Zhao, Yuxun Wang, Yunyun Zhang, Chenglong $\quad \mathrm{Xu}, \mathrm{Xu} \quad$ Wang, Shifa* \\ (Co-Innovation Center of Efficient Processing and Utilization of Forest Resources, College of Chemical Engineering, \\ Nanjing Forestry University, Nanjing 210037)
}

\begin{abstract}
Based on the combination principle in drug design, a series of camphor sulfamoxime ether derivatives were designed and synthesized with (+)-10-camphorsulfonic acid as the staring materials via acyl chlorination, acyl amidation and condensation. The target compounds were characterized by ${ }^{1} \mathrm{H}$ NMR, ${ }^{13} \mathrm{C}$ NMR and HRMS spectra. In addition, the antiproliferative effects of compounds were evaluated on a panel of human adherent cell lines (A549, Hela, MCF-7 and LO2) by means of methyl thiazolyl tetrazolium (MTT) assays. Noticeably, (+)-1-(2-((benzyloxy)imino)-7,7-dimethylbicyclo[2.2.1]-heptan1-yl)- $N$-(3-(trifluoromethyl)phenyl)methanesulfonamide (4r) possessed excellent antiproliferative against A549 (6.75 $\mu \mathrm{mol}$ • $\left.\mathrm{L}^{-1}\right)$, Hela $\left(7.93 \mu \mathrm{mol} \cdot \mathrm{L}^{-1}\right)$ and MCF-7 $\left(4.51 \mu \mathrm{mol} \cdot \mathrm{L}^{-1}\right)$. Flow cytometry was used to detect cell cycle progression and apoptosis, and morphological change of apoptosis was observed by Hoechst 33258 staining. Levels of reactive oxygen specy (ROS) and mitochondrial membrane potential were measured by DCFH-DA and JC-1, respectively. These results indicated that compound $\mathbf{4 r}$ could cause cell cycle arrest at G0/G1 phase and triggered apoptosis in MCF-7 cells. Furthermore, $4 \mathbf{r}$ could induce the accumulation of ROS and mitochondrial disruption. Taken together, compound $\mathbf{4 r}$ could be a potential anticancer drug candidate.
\end{abstract}

Keywords camphor sulfamoxime ether; antitumor activity; G0/G1 phase arrest; apoptosis

\section{Introduction}

Malignant tumor has been regarded as one of the major public health problems which threatens people's health seriously. According to the estimation from World Health Organization (WHO), more than four million people are diagnosed with cancer each year and five patients dying of it almost every minute. ${ }^{[1-2]}$ Although an increasing number of antitumor drugs have been explored to date, side effects of these drugs, such as toxicity, drug resistance and lack of selectivity, are still a severe issue. ${ }^{[3-4]}$ Therefore, it is of great necessity to screen for more efficient and safer antitumor drug candidates.

Oxime ether $\left(\mathrm{R}^{1} \mathrm{R}^{2} \mathrm{C}=\mathrm{NOR}\right)$, containing aldoxime (a,

* Corresponding author. E-mail: wangshifa65@163.com

Received September 24, 2020; revised October 22, 2020; published online November 28, 2020.

Project supported by the Natural National Science Foundation of China (No. 32071707).

国家自然科学基金(No. 32071707)资助项目. 
Figure 1) or ketoxime $O$-ethers (b), are one of the most versatile synthons in organic synthesis, and can be converted to a series of nitrogen containing compounds through hydrolysis, cyclization or cross coupling. ${ }^{[5-7]}$ Compounds bearing oxime ether groups are valued not only for their synthetic utility, but also for their biological properties including antifungal, ${ }^{[8-9]}$ antiviral, ${ }^{[10]}$ and anticancer applications. ${ }^{[11-12]}$ In particular, oxime ethers, which could improve the solubility and bioavailability of drug molecules, had been widely used in the study of anti-tumor drugs. A series of novel $\alpha, \beta$-unsaturated carbonyl based oxime ether analogs were designed and these compounds exerted modest cytotoxicity towards human cancer cell lines, out of which compound $\mathbf{c}$ exhibited the EGFR TK inhibitory activity comparable to erlotinib with an $\mathrm{IC}_{50}$ of $0.10 \mu \mathrm{mol} \cdot \mathrm{L}^{-1} \cdot{ }^{[13]}$ Cui et al. ${ }^{[14]}$ found that compound $\mathbf{d}$, bearing $\mathrm{O}$-short carbon chains, could significantly increase the large conductance calcium-activated potassium channel-opening activity. Moreover, indeno[1,2-c]quinoline derivative (e) had been considered as a new class of molecules that has the potential to be developed as topoisomerases (topo I and topo II) inhibitory agents. ${ }^{[15]}$ Based on these findings, oxime ether and its derivatives have been proved to be promising compounds for development of innovative anticancer agents.

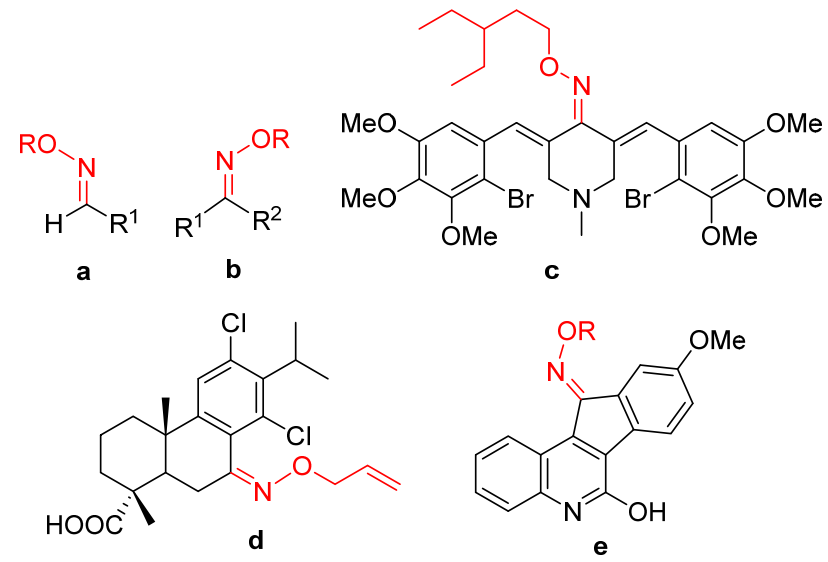

Figure 1 Chemical structures of oxime ethers and their derivatives

Natural compounds, possessing unique chemical skeleton, have the ability to bind with specific targets and exhibit various mechanisms of action, which are considered to be a treasure for drug development. ${ }^{[16-17]}$ Camphorsulfonic acid can be obtained from renewable natural product camphor by sulfonation and has become an indispensable scaffold in light chemical engineering and daily chemical industry. ${ }^{[18]}$ Besides, a lot of camphorsulfonic acid derivatives had shown prominent anticancer activity through various mechanisms including DNA binding or cleaving and induction of apoptosis or oncosis. ${ }^{[19]}$ In addition, a lot of scientific literature had reported that antitumor agents possessing the feature structure of sulfonamide. ${ }^{[20-21]}$ Hence, it is worthwhile to further modify the structure of camphorsulfonic acid with sulfonamide and study its bio- logical activity.

Based on the importance of oxime ethers and sulfonamide moieties in anticancer activity, it was considered that simultaneous administration of above-mentioned structures in a single molecule would exhibit a more potent antitumor activity. Hence, we designed and synthesized 18 novel camphor sulfamoxime ether derivatives to screen novel anticancer agents. The synthesized compounds were evaluated for the anticancer activity against non-small cell lung cancer cells (A549), human cervical cancer cells (Hela) and human breast cancer cells (MCF-7) by methyl thiazolyl tetrazolium (MTT) assay. In addition, the possible mechanisms of cell apoptosis were preliminarily probed.

\section{Results and discussion}

\subsection{Synthesis and characterization}

A series of camphor sulfamoxime ether derivatives were synthesized from $(+)$-10-camphorsulfonic acid 1, following depicted the route in Scheme 1. Intermediate 2 was synthesized based on a modified literature procedure. ${ }^{[22-23]}$ Compounds $\mathbf{3 a} \sim \mathbf{3 f}$ were generated by sulfonamidation of compound $\mathbf{2}$ with substituted amines in acetonitrile at $0 \quad{ }^{\circ} \mathrm{C} .^{[24]}$ Subsequently, compounds $\mathbf{3 a} \sim \mathbf{3 f}$ and alkoxyamine hydrochlorides were added to ethanol to obtain oxime ether analogues $4 \mathbf{a} \sim \mathbf{4 r}$. Moreover, the structures of target compounds were characterized by NMR and HRMS.

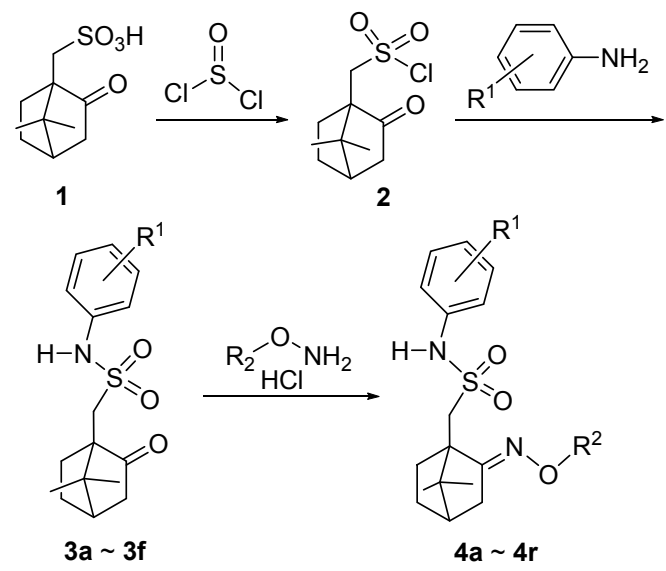

4a: $\mathrm{R}^{1}=p-\mathrm{H}, \mathrm{R}^{2}=\mathrm{CH}_{3} ; \mathbf{4 g}: \mathrm{R}^{1}=m-\mathrm{C}, \mathrm{R}^{2}=\mathrm{CH}_{3} ; \mathbf{4 m}: \mathrm{R}^{1}=p-\mathrm{Cl}$, $\mathrm{R}^{2}=\mathrm{CH}_{3} ; \mathbf{4 b}: \mathrm{R}^{1}=p-\mathrm{H}, \mathrm{R}^{2}=\mathrm{CH}_{3} \mathrm{CH}_{2} \mathrm{CH}_{2} \mathrm{CH}_{2} ; \mathbf{4 h}: \mathrm{R}^{1}=m-\mathrm{Cl}$, $\mathrm{R}^{2}=\mathrm{CH}_{3} \mathrm{CH}_{2} \mathrm{CH}_{2} \mathrm{CH}_{2} ; \mathbf{4 n}: \mathrm{R}^{1}=p-\mathrm{Cl}, \mathrm{R}^{2}=\mathrm{CH}_{3} \mathrm{CH}_{2} \mathrm{CH}_{2} \mathrm{CH}_{2}$; 4c: $\mathrm{R}^{1}=p-\mathrm{H}, \mathrm{R}^{2}=\mathrm{CH}_{2} \mathrm{C}_{6} \mathrm{H}_{5} ; 4 \mathrm{i}: \mathrm{R}^{1}=m-\mathrm{Cl}, \mathrm{R}^{2}=\mathrm{CH}_{2} \mathrm{C}_{6} \mathrm{H}_{5} ; \mathbf{4 0}$ : $\mathrm{R}^{1}=p-\mathrm{Cl}, \mathrm{R}^{2}=\mathrm{CH}_{2} \mathrm{C}_{6} \mathrm{H}_{5} ; \mathbf{4 d}: \mathrm{R}^{1}=m-\mathrm{OMe}, \mathrm{R}^{2}=\mathrm{CH}_{3} ; \mathbf{4 j}: \mathrm{R}^{1}=$ p-OMe, $\mathrm{R}^{2}=\mathrm{CH}_{3} ; \mathbf{4 p}: \mathbf{R}^{1}=m-\mathrm{CF}_{3}, \mathbf{R}^{2}=\mathrm{CH}_{3} ; \mathbf{4 e}: \mathbf{R}^{1}=m-\mathrm{OMe}$, $\mathrm{R}^{2}=\mathrm{CH}_{3} \mathrm{CH}_{2} \mathrm{CH}_{2} \mathrm{CH}_{2} ; \mathbf{4 k}: \mathrm{R}^{1}=p-\mathrm{OMe}, \mathrm{R}^{2}=\mathrm{CH}_{3} \mathrm{CH}_{2} \mathrm{CH}_{2} \mathrm{CH}_{2}$; 4q: $\mathbf{R}^{1}=m-\mathrm{CF}_{3}, \mathbf{R}^{2}=\mathrm{CH}_{3} \mathrm{CH}_{2} \mathrm{CH}_{2} \mathrm{CH}_{2} ; \mathbf{4 f :} \mathbf{R}^{1}=m-\mathrm{OMe}, \mathbf{R}^{2}=$ $\mathrm{CH}_{2} \mathrm{C}_{6} \mathrm{H}_{5} ; 4 \mathrm{I}: \mathrm{R}^{1}=p-\mathrm{OMe}, \mathrm{R}^{2}=\mathrm{CH}_{2} \mathrm{C}_{6} \mathrm{H}_{5} ; 4 \mathrm{r}: \mathrm{R}^{1}=m-\mathrm{CF}_{3}$, $\mathrm{R}^{2}=\mathrm{CH}_{2} \mathrm{C}_{6} \mathrm{H}_{5}$

\section{Scheme 1 Synthesis of compounds $4 a \sim 4 r$}

\subsection{Biological evaluation}

The antiproliferative activity of the synthetic compounds was assayed against three cancer cell lines, including A549, Hela and MCF-7 via MTT assay with etoposide as positive control. The preliminary screening results of syn- 
thesized derivatives $\mathbf{4 a} \sim \mathbf{4 r}$ have been summarized in Table 1. It was observed that four compounds $\mathbf{4 c}, \mathbf{4 i}, \mathbf{4 q}, \mathbf{4 r}$ exhibited effective antiproliferative activity against three cancer cells $\left(\mathrm{IC}_{50}\right.$ values of $\left.4.51 \sim 12.43 \mu \mathrm{mol} \cdot \mathrm{L}^{-1}\right)$. Among these derivatives, compound $4 \mathbf{r}$ showed the most potential antitumor activity with $\mathrm{IC}_{50}$ values of 6.75 (A549 cell line), 7.93 (Hela cell line) and $4.51 \mu \mathrm{mol} \cdot \mathrm{L}^{-1}(\mathrm{MCF}-7$ cell line), which were comparable to the positive control (9.86, 8.68 and $6.44 \mu \mathrm{mol} \cdot \mathrm{L}^{-1}$, respectively). In addition, compounds 4f, 4g, 4n and 4o also exhibited good inhibitory activity to Hela cell line and MCF-7 cell line while compounds $\mathbf{4 d}, \mathbf{4 j}, \mathbf{4 m}$ were only active to A-549 cells.

According to these results, some interesting structure-activity relationships (SAR) could be found. As shown in Table 1, it was obviously that derivatives $\mathbf{4 a}, \mathbf{4 b}$, 4c with no substituent on benzene rings had relatively weak anticancer activity. Furthermore, the benzene rings with the eletron-withdrawing groups $\left(\mathrm{Cl}\right.$ and $\left.\mathrm{CF}_{3}\right)$ were more effective to the cytotoxic activity than those of electron-donating ones (OMe), and the trifluoromethyl or chloro group on $m$-position also seemed more favorable than those on $p$-position. In addition, comparison of the activity of the derivatives in the series revealed that the presence of benzylhydroxylamine $\left(\mathrm{R}^{2}=\mathrm{CH}_{2} \mathrm{C}_{6} \mathrm{H}_{5}\right)$ had a greater impact on the anticancer activity when compared with other alkyl chains. On the other hand, the length of alkyl chain length also affected the antiproliferative activity to some extent. It was noticed that most of the target compounds did not show notable cytotoxicity toward LO2 cells $\left(\mathrm{IC}_{50}>50 \mu \mathrm{mol} \cdot \mathrm{L}^{-1}\right)$, whereas the positive control had high toxicity $\left(\mathrm{IC}_{50}=16.74 \mu \mathrm{mol} \cdot \mathrm{L}^{-1}\right)$.

Table 1 Antiproliferative activities of compounds $\mathbf{4 a} \sim \mathbf{4 r}$

\begin{tabular}{cllll}
\hline \multirow{2}{*}{ Compd. } & \multicolumn{4}{c}{$\mathrm{IC}_{50} /\left(\mu \mathrm{mol} \cdot \mathrm{L}^{-1}\right)$} \\
\cline { 2 - 5 } $\mathbf{4 a}$ & \multicolumn{1}{c}{$\mathrm{A}-549$} & \multicolumn{1}{c}{ Hela } & \multicolumn{1}{c}{$\mathrm{MCF}-7$} & \multicolumn{1}{c}{$\mathrm{LO} 2$} \\
$\mathbf{4 b}$ & $10.55 \pm 0.09$ & $18.93 \pm 0.03$ & $11.97 \pm 0.04$ & $45 \pm 0.13$ \\
$\mathbf{4 c}$ & $10.17 \pm 0.02$ & $7.69 \pm 0.06$ & $12.43 \pm 0.08$ & $>50$ \\
$\mathbf{4 d}$ & $14.80 \pm 0.13$ & $>50$ & $>50$ & $>50$ \\
$\mathbf{4 e}$ & $12.63 \pm 0.06$ & $13.59 \pm 0.12$ & $18.96 \pm 0.04$ & $42.18 \pm 0.07$ \\
$\mathbf{4 f}$ & $7.50 \pm 0.06$ & $49.99 \pm 0.03$ & $18.90 \pm 0.04$ & $>50$ \\
$\mathbf{4 g}$ & $16.77 \pm 0.08$ & $38.13 \pm 0.12$ & $17.71 \pm 0.12>50$ \\
$\mathbf{4 h}$ & $17.68 \pm 0.12$ & $6.83 \pm 0.06$ & $7.87 \pm 0.03$ & $33.12 \pm 0.20$ \\
$\mathbf{4 i}$ & $8.29 \pm 0.06$ & $6.69 \pm 0.06$ & $8.50 \pm 0.07$ & $46.70 \pm 0.20$ \\
$\mathbf{4 j}$ & $10.32 \pm 0.09$ & $>50$ & $>50$ & $>50$ \\
$\mathbf{4 k}$ & $12.23 \pm 0.10$ & $27.07 \pm 0.06$ & $42.19 \pm 0.10>50$ \\
$\mathbf{4 l}$ & $14.41 \pm 0.02$ & $49.99 \pm 0.02$ & $>50$ & $>50$ \\
$\mathbf{4 m}$ & $13.69 \pm 0.10$ & $>50$ & $>50$ & $31.33 \pm 0.12$ \\
$\mathbf{4 n}$ & $9.25 \pm 0.07$ & $15.64 \pm 0.09$ & $21.30 \pm 0.14$ & $30.25 \pm 0.22$ \\
$\mathbf{4 o}$ & $6.80 \pm 0.06$ & $10.04 \pm 0.04$ & $27.82 \pm 0.06$ & $43.15 \pm 0.16$ \\
$\mathbf{4 p}$ & $13.48 \pm 0.03$ & $30.96 \pm 0.06$ & $29.25 \pm 0.05$ & $>50$ \\
$\mathbf{4 q}$ & $9.00 \pm 0.11$ & $5.32 \pm 0.12$ & $6.73 \pm 0.08$ & $>50$ \\
$\mathbf{4 r}$ & $6.75 \pm 0.05$ & $7.93 \pm 0.03$ & $4.51 \pm 0.03$ & $45.13 \pm 0.20$ \\
Etoposide & $9.86 \pm 0.05$ & $8.68 \pm 0.06$ & $6.44 \pm 0.10$ & $16.74 \pm 0.03$ \\
\hline
\end{tabular}

\subsection{Cell cycle analysis}

To determine whether the inhibition to cancer cell growth that caused by compound $4 \mathbf{r}$ was correlated with cell cycle arrest, and ell cycle assay was conducted by flow cytometry. After treatment with $0,2.5,5$ and $10 \mu \mathrm{mol} \cdot \mathrm{L}^{-1}$ of compound $4 \mathbf{r}, \mathrm{MCF}-7$ cells were stained with propidium iodide (PI) and the cell cycle distribution was detected by flow cytometry. The results presented in Figure 2 clearly showed that cells in $\mathrm{G} 0 / \mathrm{G} 1$ phases increased significantly after treatment with compound 4r, from 55.08\% (0 $\mu$ mol • $\left.\mathrm{L}^{-1}\right)$ to $56.36 \%\left(2.5 \mu \mathrm{mol} \cdot \mathrm{L}^{-1}\right), 63.44 \%\left(5 \mu \mathrm{mol} \cdot \mathrm{L}^{-1}\right)$ and $66.41 \%\left(10 \mu \mathrm{mol} \cdot \mathrm{L}^{-1}\right)$. Meanwhile, cells in $\mathrm{G} 2 / \mathrm{M}$ phase decreased from $19.65 \%$ (control) to $10.73 \%$ (10 $\mu \mathrm{mol}$ • $\mathrm{L}^{-1}$ ), respectively. These analyses indicated that $4 \mathbf{r}$ caused a remarkable G0/G1 phase arrest in a concentration-dependent manner.

\subsection{Cell apoptosis analysis}

In order to confirm whether the growth inhibitory effects of compound $4 r$ on tumor cells were caused by cell apoptosis, MCF-7 cells were treated with different concentrations of compound $4 \mathbf{r}\left(0,2.5,5\right.$ and $\left.10 \mu \mathrm{mol} \cdot \mathrm{L}^{-1}\right)$, and evaluated by Hoechst 33258 dye and Annexin V-FITC/PI. As shown in Figure 3a, most of the cells exhibited weak blue fluorescence in the control group. On the contrary, some cells emitted brilliant blue fluorescence and nucleus were condensed or fragmented in a dose-dependent manner after the treatment with compound 4r. To further verified the apoptotic rate of compound $\mathbf{4 r}$ in MCF-7 cells, Annexin V-FITC/PI staining was conducted, followed by flow cytometry (Figures $3 \mathrm{~b}$ and $3 \mathrm{c}$ ). The proportion of apoptotic cells (including early and late apoptosis) with higher dose of compound $\mathbf{4 r}$ were observed as $21.19 \%$, which was significantly higher as compared to control (MCF-7 cells showing apoptotic rate $11.63 \%$ ). Besides, the cell apoptosis rate was increased gradually when the dose of compound 4r was increased. These results provided apparent evidence that compound $4 r$ could effectively induce apoptosis in MCF-7 cells via a dose-dependent manner.

\subsection{Intracellular ROS level analysis}

Reactive oxygen species (ROS) play a crucial role in intracellular signaling and regulation. In particular, low levels of ROS promote tumor growth, whereas excess ROS can result in apoptosis of cancer cells. ${ }^{[25-26]}$ To further comprehend whether compound $4 \mathbf{r}$ triggers ROS generation in MCF-7 cells to induce apoptosis, the ROS levels in MCF-7 cells were investigated via the oxidant-sensing fluorescent probe 2,7-dichlorodihydrofluorescein diacetate (DCFH-DA), which can be converted into 2',7'-dichlorofluorescein (DCF) with green fluorescence upon the exposure to ROS. As shown in Figure 4, cells treated with increasing concentration of compound $4 \mathbf{r}$ remarkably increased in green fluorescence intensity compared to control group, which only exhibited weak green fluorescence. These results strongly suggested that compound $\mathbf{4 r}$ could increase intracellular ROS levels in MCF-7 cells, which was a key factor in its anticancer activity and could cause the oxidative stress. 

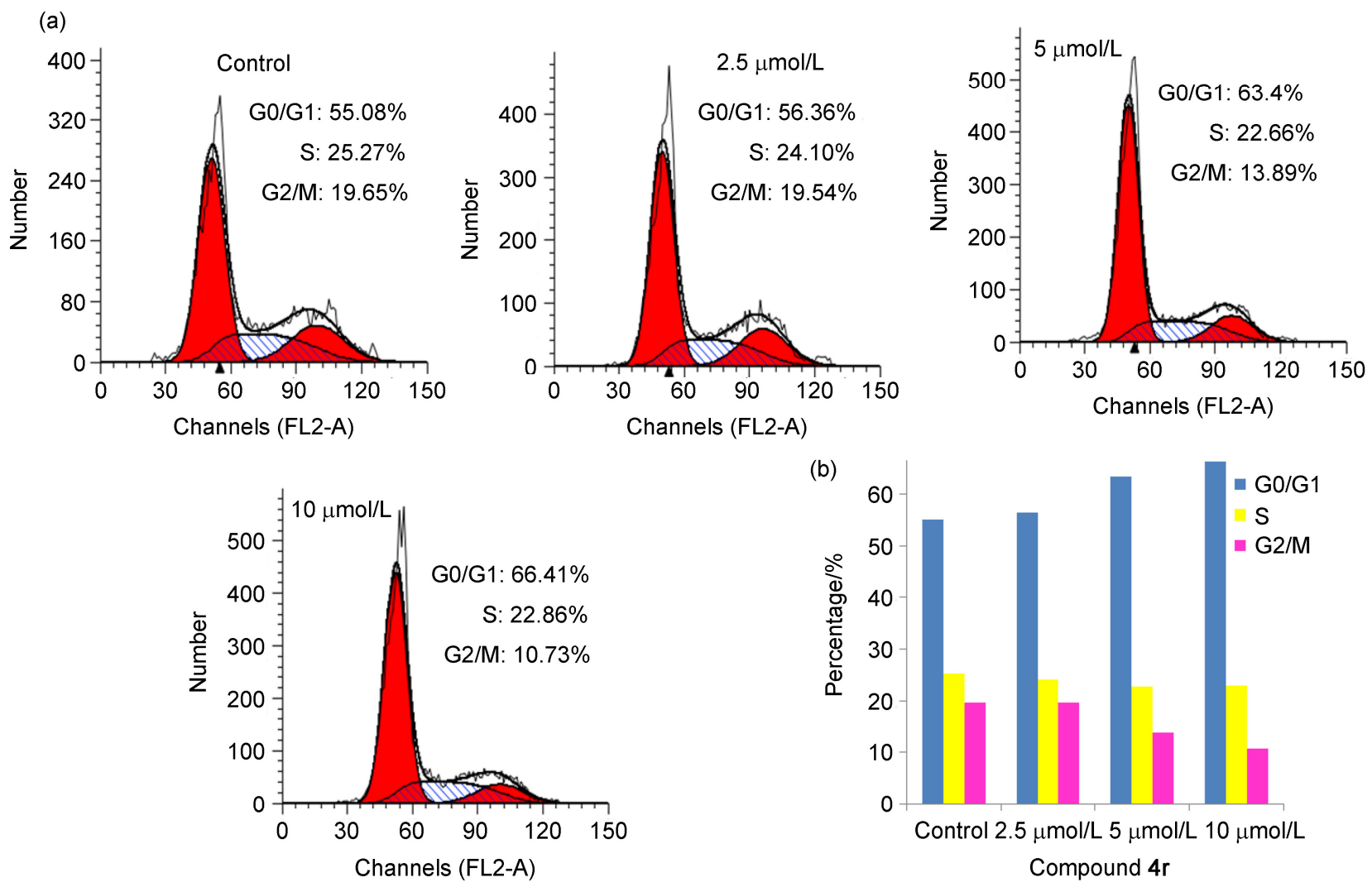

Figure 2 Cell cycle analysis of compound $\mathbf{4 r}$ in MCF-7 cells

(a) Cell cycle distribution upon treatment with compound $\mathbf{4 r}$ at different concentrations $\left(0,2.5,5,10 \mu \mathrm{mol} \cdot \mathrm{L}^{-1}\right)$ for $24 \mathrm{~h}$ in MCF-7 cells; (b) The statistical analysis of MCF-7 cells in the different phases of cell cycle was presented

\subsection{Mitochondrial membrane potential analysis}

As an important organelle, mitochondrion plays key roles in cells, not only supplying metabolic energy in the form of adenosine triphosphate, but also being involved in a variety of cellular apoptotic progresses. ${ }^{[27-29]}$ To further explore the apoptosis-inducing effect of compound $\mathbf{4 r}$, the mitochondrial membrane potential $(\Delta \Psi \mathrm{m})$ change was performed using JC- 1 , which can easily pass through the plasma membrane into cells and accumulate in mitochondria. JC-1 accumulates in intact mitochondria in the form of red fluorescent aggregates, but when the membrane potential is lost, JC-1 forms green fluorescent monomers. ${ }^{[30-31]}$ As shown in Figure 5, red fluorescence was emitted in MCF-7 cells without any treatment with compound 4r. However, the fluorescence colour changed red (J-aggregates) to green fluorescence (JC-1 monomers) in MCF-7 cells obviously when the concentration of compound $4 \mathbf{r}$ was increased. Especially in the $10 \mu \mathrm{mol} \cdot \mathrm{L}^{-1}$ group, green fluorescence was almost prevalent in all cell areas. These results clearly suggested that compound $\mathbf{4 r}$ could lead to drastic effects on mitochondrial morphology via a dose- dependent manner, which was a significant factor triggering apoptosis in MCF-7 cells.

\section{Conclusions}

In this work, 18 new oxime ether derivatives of camphorsulfonic acid were designed, synthesized, and evalu- ated for their in vitro antiproliferative potential. The in vitro antiproliferative activity screening indicated that four compounds $\mathbf{4 c}, \mathbf{4 i}, \mathbf{4 q}, \mathbf{4 r}$ exhibited the most significant antiproliferative against three cancer cell lines which were even better than the positive control etoposide, and it was found that significant improvement of anticancer activity was observed as derivatives containing both the eletronwithdrawing groups in $m$-position of benzene ring and benzylhydroxylamine. Cell-based studies showed that compound $\mathbf{4 r}$ could arrest cell cycle at G0/G1 phase and promote mainly apoptosis in MCF-7 cell line. Furthermore, $4 \mathbf{r}$ induced the accumulation of ROS and mitochondrial disruption, and thereby caused cell apoptosis in MCF-7 cells. On the basis of above studies, compound $\mathbf{4 r}$ may be regarded as a potential antitumor agent.

\section{Experimental section}

\subsection{Methods and materials}

Chemical reagents were purchased from Energy Chemical Reagent Company and used without further purification if not indicated. Analytical thin-layer chromatography (TLC) monitored the progress of reactions using Qingdao Marine silica gel plates, and developed chromatogram was visualized under $254 \mathrm{~nm}$ illumination. The crude compounds were purified by column chromatography with silica gel (Qingdao Marine, 200 300 mesh) as stationary phase. Melting points were measured on a X-4 melting 
(a)
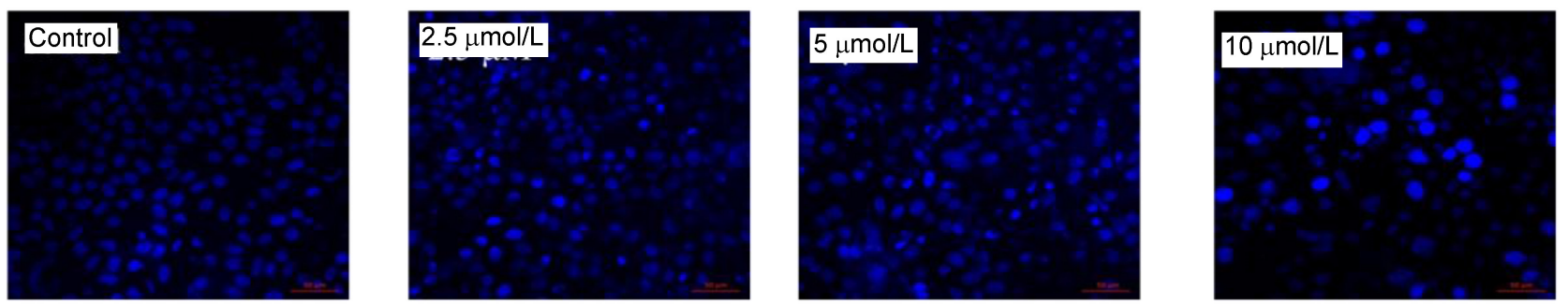

(b)
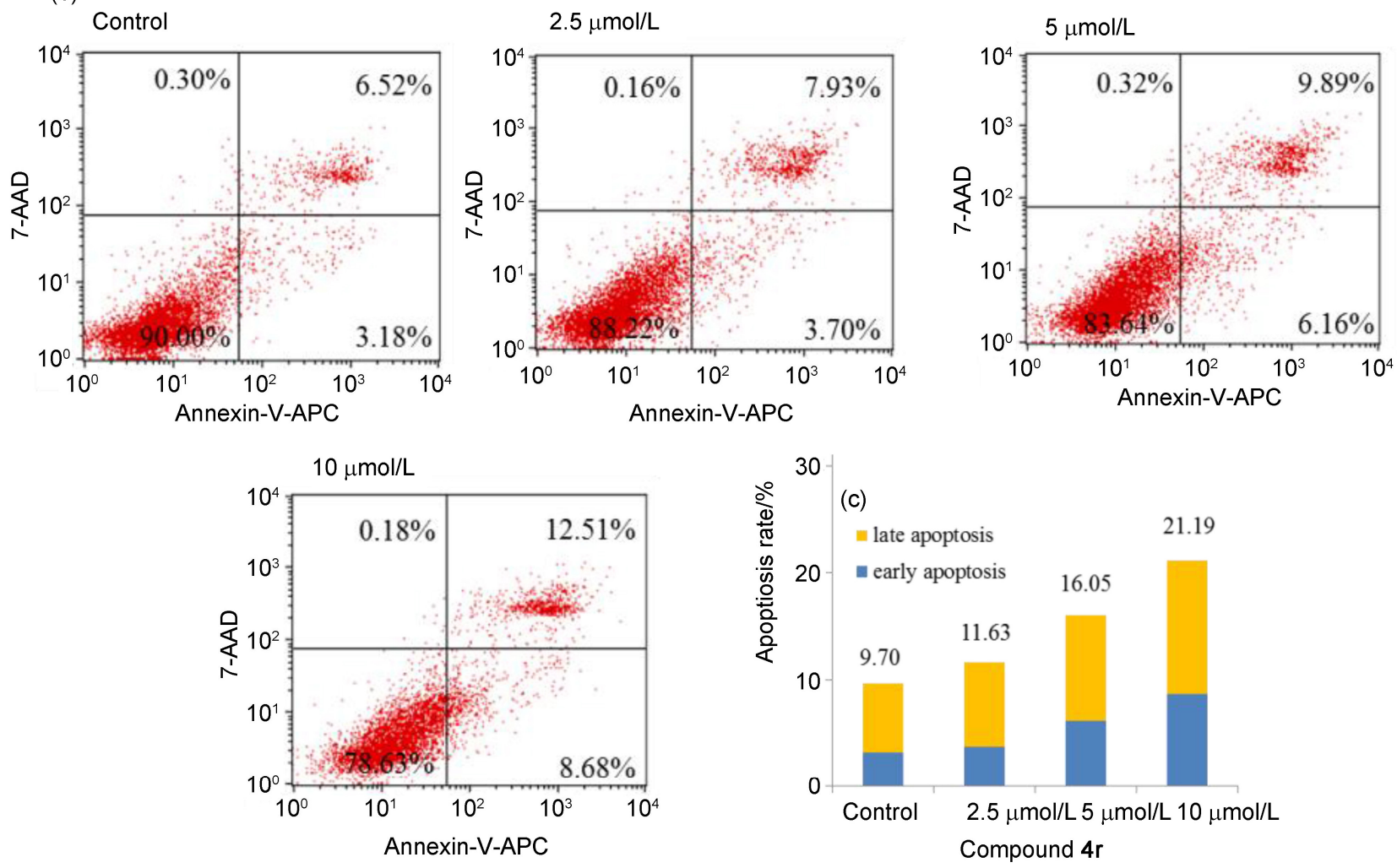

Figure 3 Cell apoptosis analysis of compound $4 \mathbf{r}$ in MCF-7 cells

(a) Hoechst 33258 staining of MCF-7 cells treated with $0,2.5,5$ and $10 \mu \mathrm{mol} \cdot \mathrm{L}^{-1}$ of compound $\mathbf{4 r}$ for $24 \mathrm{~h}$ and fluorescence was observed by confocal microscopy; (b) cell apoptosis rate upon treatment with different concentrations of compound $4 \mathbf{r}$ for $24 \mathrm{~h}$ in MCF-7 cells; (c) graphical representation of effect of compound $\mathbf{4 r}$ on cell apoptosis
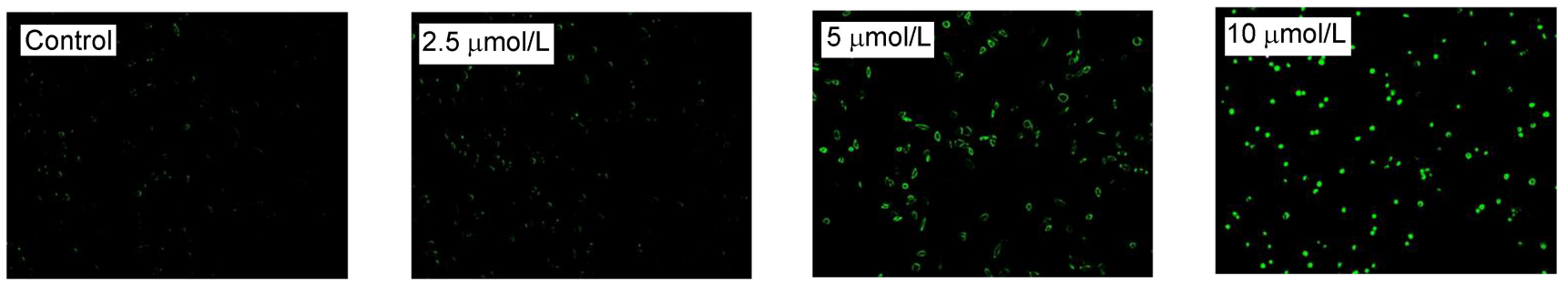

Figure 4 ROS production uantified by DCFH-DA fluorescence probe Image observations were carried out by fluorescence microscopy

apparatus (Shanghai Yice Apparatus \&Equipments Co, Ltd) and uncorrected. Specific rotations were measured on a SGW-533 polarimeter (Shanghai INESA Physico optiacal instrument Co, Ltd). ${ }^{1} \mathrm{H}$ NMR and ${ }^{13} \mathrm{C}$ NMR spectra were recorded in $\mathrm{CDCl}_{3}$ or DMSO- $d_{6}$ on Bruker $400 \mathrm{MHz}$ $\left(100 \mathrm{MHz}\right.$ for $\left.{ }^{13} \mathrm{C}\right)$ or $600 \mathrm{MHz}\left(150 \mathrm{MHz}\right.$ for $\left.{ }^{13} \mathrm{C}\right)$ nuclear resonance spectrometers. The HRMS spectra were accom- plished in Agilent 6540 high-resolution mass spectrometer.

\subsection{Chemistry}

4.2.1 Synthesis of $(+)$-10-camphorsulfonyl chloride (2)

(+)-10-Camphorsulfonyl chloride 2 was prepared following the previous published literature. ${ }^{[22-23]}(+)-10-$ Camphorsulfonic acid (1) (6.8 g, $30 \mathrm{mmol})$ was slowly 


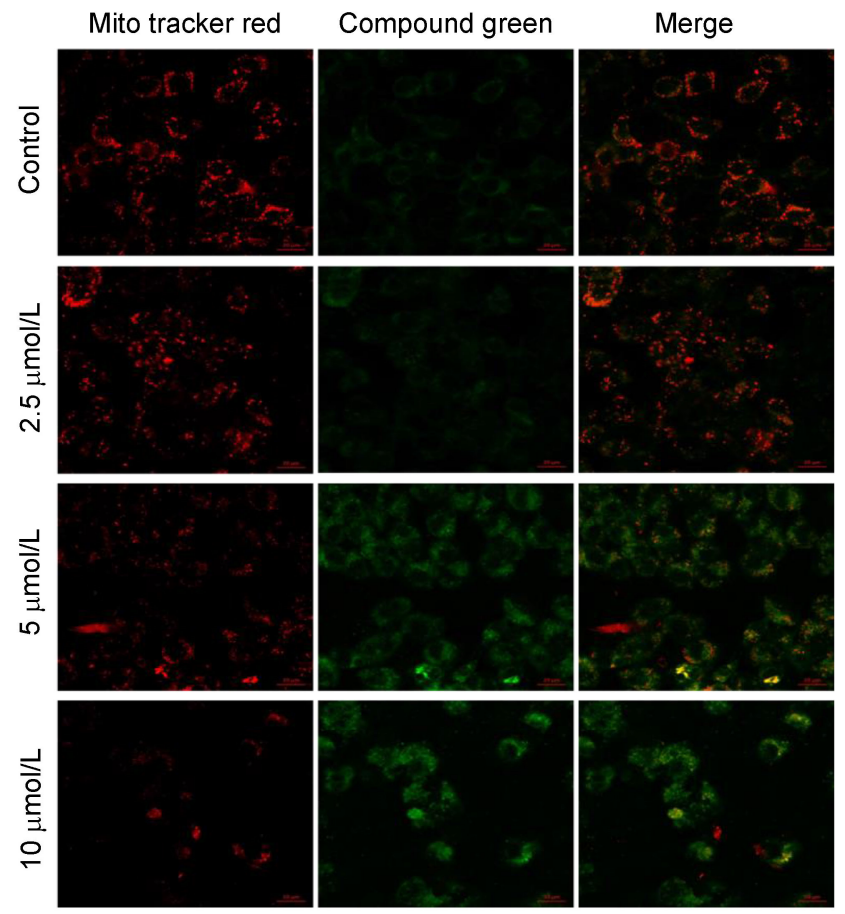

Figure $5 \Delta \Psi \mathrm{m}$ quantified by using the JC-1 JC-1 staining of MCF-7 cells treated with $0,2.5,5$ and $10 \mu \mathrm{mol} \cdot \mathrm{L}^{-1}$ of compound $4 \mathbf{r}$ for $24 \mathrm{~h}$ and images were acquired by confocal microscopy

added to a $100 \mathrm{~mL}$ dried three-necked flask at $0{ }^{\circ} \mathrm{C}$ containing $\mathrm{SOCl}_{2}(8.5 \mathrm{~mL}, 120 \mathrm{mmol})$. After stirring for 30 min at $0{ }^{\circ} \mathrm{C}$, the reaction mixture was further stirred for another $2 \mathrm{~h}$ at room temperature. Finally, the solid residue was obtained by filtration, which was further washed with ice-cold water, dried, and recrystallized from petroleum ether to afford (+)-(7,7-dimethyl-2-oxobicyclo[2.2.1]heptan-1-yl)methanesulfonyl chloride (2) with $73 \%$ yield. ${ }^{1} \mathrm{H}$ $\operatorname{NMR}\left(600 \mathrm{MHz}, \mathrm{CDCl}_{3}\right) \delta: 4.32(\mathrm{~d}, J=14.6 \mathrm{~Hz}, 1 \mathrm{H}), 3.75$ (d, $J=14.6 \mathrm{~Hz}, 1 \mathrm{H}), 2.53 \sim 2.41(\mathrm{~m}, 2 \mathrm{H}), 2.18(\mathrm{t}, J=4.6$ $\mathrm{Hz}, 1 \mathrm{H}), 2.16 \sim 2.07(\mathrm{~m}, 1 \mathrm{H}), 2.01(\mathrm{~d}, J=18.6 \mathrm{~Hz}, 1 \mathrm{H})$, $1.82 \sim 1.76(\mathrm{~m}, 1 \mathrm{H}), 1.54 \sim 1.47(\mathrm{~m}, 1 \mathrm{H}), 1.16(\mathrm{~s}, 3 \mathrm{H}), 0.94$ (s, 3H) ${ }^{13} \mathrm{C}$ NMR $\left(151 \mathrm{MHz}, \mathrm{CDCl}_{3}\right) \delta: 212.5,64.3,59.7$, $48.15,42.8,42.3,26.8,25.3,19.7,19.6$.

\subsubsection{General procedure for the synthesis of $\mathbf{3 a} \sim \mathbf{3 f}$}

A mixture of compound 2 (1.5 g, $6 \mathrm{mmol})$, substituted aniline $(6 \mathrm{mmol})$ and 4-dimethylaminopyridine $(0.36 \mathrm{~g}, 3$ mmol) were dissolved in acetonitrile and stirred for $3 \mathrm{~h}$ at $0{ }^{\circ} \mathrm{C}$. When the reaction was completed (monitored by TLC), the reaction solvent was removed under vacuum and the mixture was poured into saturated aqueous sodium chloride solution $(50 \mathrm{~mL})$ and extracted with ethyl acetate $(50 \mathrm{~mL} \times 3)$. The organic layers were combined and dried over anhydrous sodium sulfate, evaporated in vacuum and then purified by recrystallization from petroleum ether.

(+)-1-(7,7-Dimethyl-2-oxobicyclo[2.2.1]heptan-1-yl)- $N$ phenylmethanesulfonamide (3a): Yield 81\%. ${ }^{1} \mathrm{H}$ NMR $\left(600 \mathrm{MHz}, \mathrm{CDCl}_{3}\right) \delta: 7.76(\mathrm{~s}, 1 \mathrm{H}), 7.37 \sim 7.33(\mathrm{~m}, 2 \mathrm{H})$, $7.33 \sim 7.28(\mathrm{~m}, 2 \mathrm{H}), 7.22 \sim 7.17(\mathrm{~m}, 1 \mathrm{H}), 3.41(\mathrm{~d}, J=15.3$ $\mathrm{Hz}, 1 \mathrm{H}), 2.90(\mathrm{~d}, J=15.3 \mathrm{~Hz}, 1 \mathrm{H}), 2.50 \sim 2.41(\mathrm{~m}, 1 \mathrm{H})$, $2.18 \sim 2.12(\mathrm{~m}, 3 \mathrm{H}), 2.10 \sim 2.02(\mathrm{~m}, 1 \mathrm{H}), 1.99(\mathrm{~d}, J=$
$18.7 \mathrm{~Hz}, 1 \mathrm{H}), 1.52 \sim 1.46(\mathrm{~m}, 1 \mathrm{H}), 0.99(\mathrm{~s}, 3 \mathrm{H}), 0.87(\mathrm{~s}$, $3 \mathrm{H}) ;{ }^{13} \mathrm{C}$ NMR $\left(150 \mathrm{~Hz}, \mathrm{CDCl}_{3}\right) \delta: 217.2,137.6,129.4$, 125.4, 122.0, 59.6, 49.0, 43.0, 42.8, 27.5, 27.0, 19.8, 19.3.

(+)-1-(7,7-Dimethyl-2-oxobicyclo[2.2.1] heptan-1-yl)- $N$ (3-metho xyphenyl)methanesulfonamide (3b): Yield 92\%. ${ }^{1} \mathrm{H}$ NMR $\left(600 \mathrm{MHz}, \mathrm{CDCl}_{3}\right) \delta: 7.80(\mathrm{~s}, 1 \mathrm{H}), 7.23(\mathrm{t}, J=8.1$ $\mathrm{Hz}, 1 \mathrm{H}), 6.93(\mathrm{t}, J=2.3 \mathrm{~Hz}, 1 \mathrm{H}), 6.88 \sim 6.82(\mathrm{~m}, 1 \mathrm{H})$, $6.76 \sim 6.70(\mathrm{~m}, 1 \mathrm{H}), 3.81(\mathrm{~s}, 3 \mathrm{H}), 3.44(\mathrm{~d}, J=15.2 \mathrm{~Hz}$, $1 \mathrm{H}), 2.92(\mathrm{~d}, J=15.2 \mathrm{~Hz}, 1 \mathrm{H}), 2.49 \sim 2.39(\mathrm{~m}, 1 \mathrm{H}), 2.20 \sim$ $2.05(\mathrm{~m}, 3 \mathrm{H}), 2.09 \sim 2.01(\mathrm{~m}, 1 \mathrm{H}), 1.98(\mathrm{~d}, J=18.7 \mathrm{~Hz}$, $1 \mathrm{H}), 1.53 \sim 1.44(\mathrm{~m}, 1 \mathrm{H}), 0.98(\mathrm{~s}, 3 \mathrm{H}), 0.86(\mathrm{~s}, 3 \mathrm{H}) ;{ }^{13} \mathrm{C}$ NMR $\left(150 \mathrm{~Hz}, \mathrm{CDCl}_{3}\right) \delta: 217.1,160.4,138.8,130.1$, $113.8,111.2,107.4,59.5,55.3,49.0,48.9,43.0,42.8,27.4$, 27.0, 19.8, 19.3.

(+)- $N$-(3-Chlorophenyl)-1-(7,7-dimethyl-2-oxobicyclo[2.2.1] heptan-1-yl)methanesulfonamide (3c): Yield 79\%. ${ }^{1} \mathrm{H}$ NMR (600 MHz, $\left.\mathrm{CDCl}_{3}\right) \delta: 7.93(\mathrm{~s}, 1 \mathrm{H}), 7.36(\mathrm{t}, J=2.1$ $\mathrm{Hz}, 1 \mathrm{H}), 7.27(\mathrm{~d}, J=8.0 \mathrm{~Hz}, 1 \mathrm{H}), 7.23 \sim 7.18(\mathrm{~m}, 1 \mathrm{H})$, $7.19 \sim 7.14(\mathrm{~m}, 1 \mathrm{H}), 3.39(\mathrm{~d}, J=15.3 \mathrm{~Hz}, 1 \mathrm{H}), 2.94(\mathrm{~d}, J=$ $15.3 \mathrm{~Hz}, 1 \mathrm{H}), 2.51 \sim 2.43(\mathrm{~m}, 1 \mathrm{H}), 2.19 \sim 2.11(\mathrm{~m}, 3 \mathrm{H})$, $2.11 \sim 2.03(\mathrm{~m}, 1 \mathrm{H}), 2.00(\mathrm{~d}, J=18.7 \mathrm{~Hz}, 1 \mathrm{H}), 1.54 \sim 1.46$ $(\mathrm{m}, 1 \mathrm{H}), 1.00(\mathrm{~s}, 3 \mathrm{H}), 0.88(\mathrm{~s}, 3 \mathrm{H}) ;{ }^{13} \mathrm{C}$ NMR $(150 \mathrm{~Hz}$, $\left.\mathrm{CDCl}_{3}\right) \delta: 217.4,138.9,135.0,130.3,125.4,121.7,119.7$, 59.7, 49.5, 49.1, 43.0, 42.8, 27.5, 27.0, 19.8, 19.3.

(+)-1-(7,7-Dimethyl-2-oxobicyclo[2.2.1] heptan-1-yl)- $N$ (4-methoxyphenyl)methanesulfonamide (3d): Yield 90\%. ${ }^{1} \mathrm{H}$ NMR $\left(600 \mathrm{MHz}, \mathrm{CDCl}_{3}\right) \delta: 7.66$ (bs, $\left.1 \mathrm{H}\right), 7.26 \sim 7.20$ $(\mathrm{m}, 2 \mathrm{H}), 6.90 \sim 6.85(\mathrm{~m}, 2 \mathrm{H}), 3.80(\mathrm{~s}, 3 \mathrm{H}), 3.37(\mathrm{~d}, J=$ $15.3 \mathrm{~Hz}, 1 \mathrm{H}), 2.83$ (d, $J=15.3 \mathrm{~Hz}, 1 \mathrm{H}), 2.50 \sim 2.42$ (m, $1 \mathrm{H}), 2.20 \sim 2.05(\mathrm{~m}, 4 \mathrm{H}), 1.99(\mathrm{~d}, J=18.7 \mathrm{~Hz}, 1 \mathrm{H}), 1.52 \sim$ $1.45(\mathrm{~m}, 1 \mathrm{H}), 0.97(\mathrm{~s}, 3 \mathrm{H}), 0.88(\mathrm{~s}, 3 \mathrm{H}) ;{ }^{13} \mathrm{C}$ NMR $(150$ $\left.\mathrm{Hz}, \mathrm{CDCl}_{3}\right) \delta: 217.5,157.8,130.3,124.9,114.5,59.7$, $55.4,49.1,48.3,43.1,42.8,27.6,27.0,19.9,19.3$.

(+)- $N$-(4-Chlorophenyl)-1-(7,7-dimethyl-2-oxobicyclo[2.2.1] heptan-1-yl)methanesulfona mide (3e): Yield $88 \%$. ${ }^{1} \mathrm{H}$ NMR $\left(600 \mathrm{MHz}, \mathrm{CDCl}_{3}\right) \delta: 7.93(\mathrm{bs}, 1 \mathrm{H}), 7.34 \sim 7.28$ $(\mathrm{m}, 2 \mathrm{H}), 7.29 \sim 7.23(\mathrm{~m}, 2 \mathrm{H}), 3.35(\mathrm{~d}, J=15.3 \mathrm{~Hz}, 1 \mathrm{H})$, $2.90(\mathrm{~d}, J=15.3 \mathrm{~Hz}, 1 \mathrm{H}), 2.50 \sim 2.41(\mathrm{~m}, 1 \mathrm{H}), 2.21 \sim 2.04$ $(\mathrm{m}, 3 \mathrm{H}), 2.09 \sim 2.02(\mathrm{~m}, 1 \mathrm{H}), 1.99(\mathrm{~d}, J=18.7 \mathrm{~Hz}, 1 \mathrm{H})$, $1.55 \sim 1.43(\mathrm{~m}, 1 \mathrm{H}), 0.98(\mathrm{~s}, 3 \mathrm{H}), 0.87(\mathrm{~s}, 3 \mathrm{H}) ;{ }^{13} \mathrm{C} \mathrm{NMR}$ $\left(150 \mathrm{~Hz}, \mathrm{CDCl}_{3}\right) \delta: 217.6,136.2,131.0,129.8,129.4$, 123.3, 59.7, 49.1, 49.1, 43.0, 42.8, 27.5, 27.0, 19.8, 19.3.

(+)-1-(7,7-Dimethyl-2-oxobicyclo[2.2.1] heptan-1-yl)- $N$ (4-(trifluoromethyl)phenyl)methanesulfona mide (3f): Yield $86 \%$. ${ }^{1} \mathrm{H}$ NMR $\left(600 \mathrm{MHz}, \mathrm{CDCl}_{3}\right) \delta: 8.22(\mathrm{~s}, 1 \mathrm{H})$, $7.58 \sim 7.50(\mathrm{~m}, 2 \mathrm{H}), 7.51 \sim 7.43(\mathrm{~m}, 2 \mathrm{H}), 3.37(\mathrm{~d}, J=15.3$ $\mathrm{Hz}, 1 \mathrm{H}), 2.95(\mathrm{~d}, J=15.3 \mathrm{~Hz}, 1 \mathrm{H}), 2.52 \sim 2.43(\mathrm{~m}, 1 \mathrm{H})$, $2.20 \sim 2.06(\mathrm{~m}, 3 \mathrm{H}), 2.10 \sim 2.04(\mathrm{~m}, 1 \mathrm{H}), 2.01(\mathrm{~d}, J=18.8$ $\mathrm{Hz}, 1 \mathrm{H}), 1.54 \sim 1.47(\mathrm{~m}, 1 \mathrm{H}), 0.98(\mathrm{~s}, 3 \mathrm{H}), 0.86(\mathrm{~s}, 3 \mathrm{H})$; ${ }^{13} \mathrm{C}$ NMR $\left(150 \mathrm{~Hz}, \mathrm{CDCl}_{3}\right) \delta: 217.8,138.3,131.8(\mathrm{q}, J=$ $32.6 \mathrm{~Hz}), 130.0,125.0,121.9$ (q, $J=3.8 \mathrm{~Hz}), 118.4$ (q, $J=$ $3.9 \mathrm{~Hz}), 59.6,49.5,49.2,43.0,42.8,27.4,27.0,19.7,19.2$. 4.2.3 General procedure for the synthesis of $\mathbf{4 a} \sim \mathbf{4 r}$

To a solution of camphor sulfonamide derivatives $\mathbf{3 a} \sim$ 3f $(3 \mathrm{mmol})$ in $100 \mathrm{~mL}$ of anhydrous ethanol was added alkoxyamine hydrochlorides $(3 \mathrm{mmol})$ and hydrochloric 
acid $(0.3 \mathrm{~mL})$. The mixture was then refluxed for $10 \mathrm{~h}$. After the reaction was completed, the crude products were filtered and the filtrate was concentrated under reduced pressure, which was further purified via chromatography on silica gel (200-300 mesh) with petroleum ether and ethyl acetate $(V: V=15: 1)$ as elution.

$(+)-1-(2-(M e t h o x y i m i n o)-7,7-d i m e t h y l b i c y c l o[2.2 .1]-$ heptan-1-yl)- $N$-phenylmethanesulfonamide (4a): Yield $86 \%$, white solid, m.p. 99 $100{ }^{\circ} \mathrm{C} ;[\alpha]_{\mathrm{D}}^{20}+26.7$ (c 1, $\left.\mathrm{CH}_{3} \mathrm{OH}\right) ;{ }^{1} \mathrm{H} \mathrm{NMR}\left(400 \mathrm{MHz}, \mathrm{CDCl}_{3}\right) \delta: 8.84$ (bs, $\left.1 \mathrm{H}\right)$, $7.42 \sim 7.30(\mathrm{~m}, 4 \mathrm{H}), 7.27 \sim 7.18(\mathrm{~m}, 1 \mathrm{H}), 3.96(\mathrm{~s}, 3 \mathrm{H})$, $3.47(\mathrm{~d}, J=15.3 \mathrm{~Hz}, 1 \mathrm{H}), 2.95(\mathrm{~d}, J=15.3 \mathrm{~Hz}, 1 \mathrm{H}), 2.69 \sim$ $2.52(\mathrm{~m}, 1 \mathrm{H}), 2.33-2.20(\mathrm{~m}, 1 \mathrm{H}), 2.11(\mathrm{~d}, J=18.3 \mathrm{~Hz}$, $1 \mathrm{H}), 2.08 \sim 2.02(\mathrm{~m}, 1 \mathrm{H}), 2.01 \sim 1.88(\mathrm{~m}, 2 \mathrm{H}), 1.46 \sim 1.32$ $(\mathrm{m}, 1 \mathrm{H}), 0.93(\mathrm{~s}, 3 \mathrm{H}), 0.85(\mathrm{~s}, 3 \mathrm{H}) ;{ }^{13} \mathrm{C} \mathrm{NMR}(100 \mathrm{MHz}$, $\left.\mathrm{CDCl}_{3}\right) \delta: 167.9,138.2,129.3,125.6,123.1,61.5,53.2$, 51.1, 51.0, 43.0, 33.8, 30.6, 27.4, 19.6, 18.8. HRMS (ESI) calcd for $\mathrm{C}_{17} \mathrm{H}_{25} \mathrm{~N}_{2} \mathrm{O}_{3} \mathrm{~S}[\mathrm{M}+\mathrm{H}]^{+}: 337.1586$, found 337.1667 .

(+)-1-(2-(Butoxyimino)-7,7-dimethylbicyclo[2.2.1]heptan-1-yl)- $N$-phenylmethanesulfonamide (4b): Yield $85 \%$, white gum; $[\alpha]_{\mathrm{D}}^{20}+29.7\left(c 1, \mathrm{CH}_{3} \mathrm{OH}\right) ;{ }^{1} \mathrm{H}$ NMR $(400$ $\left.\mathrm{MHz}, \mathrm{CDCl}_{3}\right) \delta: 8.94(\mathrm{bs}, 1 \mathrm{H}), 7.45 \sim 7.30(\mathrm{~m}, 4 \mathrm{H}), 7.23$ $(\mathrm{t}, J=7.0 \mathrm{~Hz}, 1 \mathrm{H}), 4.24 \sim 4.05(\mathrm{~m}, 2 \mathrm{H}), 3.47(\mathrm{~d}, J=15.3$ $\mathrm{Hz}, 1 \mathrm{H}), 2.95(\mathrm{~d}, J=15.3 \mathrm{~Hz}, 1 \mathrm{H}), 2.70 \sim 2.56(\mathrm{~m}, 1 \mathrm{H})$, $2.34 \sim 2.20(\mathrm{~m}, 1 \mathrm{H}), 2.12(\mathrm{~d}, J=18.3 \mathrm{~Hz}, 1 \mathrm{H}), 2.08 \sim 1.99$ $(\mathrm{m}, 1 \mathrm{H}), 2.00 \sim 1.86(\mathrm{~m}, 2 \mathrm{H}), 1.74 \sim 1.61(\mathrm{~m}, 2 \mathrm{H}), 1.49 \sim$ $1.31(\mathrm{~m}, 3 \mathrm{H}), 1.05 \sim 0.89(\mathrm{~m}, 6 \mathrm{H}), 0.86(\mathrm{~s}, 3 \mathrm{H}) ;{ }^{13} \mathrm{C} \mathrm{NMR}$ $\left(100 \mathrm{MHz}, \mathrm{CDCl}_{3}\right) \delta: 167.6,138.2,129.34,125.6,123.2$, 73.7, 53.2, 51.1, 51.0, 43.1, 33.9, 31.1, 30.7, 27.4, 19.6, 19.2, 18.8, 13.9. HRMS (ESI) calcd for $\mathrm{C}_{20} \mathrm{H}_{31} \mathrm{~N}_{2} \mathrm{O}_{3} \mathrm{~S}[\mathrm{M}$ $+\mathrm{H}]^{+}: 379.2055$, found 379.2058 .

(+)-1-(2-((Benzyloxy)imino)-7,7-dimethylbicyclo[2.2.1]heptan-1-yl)- $N$-phenylmethanesulfonamide (4c): Yield $86 \%$, white solid, m.p. $88 \sim 89{ }^{\circ} \mathrm{C} ;[\alpha]_{\mathrm{D}}^{20}+28.1$ (c 1, $\left.\mathrm{CH}_{3} \mathrm{OH}\right) ;{ }^{1} \mathrm{H}$ NMR (400 MHz, $\left.\mathrm{CDCl}_{3}\right) \delta: 8.45$ (bs, $\left.1 \mathrm{H}\right)$, $7.40 \sim 7.27(\mathrm{~m}, 4 \mathrm{H}), 7.30 \sim 7.22(\mathrm{~m}, 1 \mathrm{H}), 7.24 \sim 7.19(\mathrm{~m}$, $2 \mathrm{H}), 7.19 \sim 7.14(\mathrm{~m}, 1 \mathrm{H}), 7.07 \sim 6.98(\mathrm{~m}, 2 \mathrm{H}), 5.21(\mathrm{~d}, J=$ $12.6 \mathrm{~Hz}, 1 \mathrm{H}), 5.14(\mathrm{~d}, J=12.6 \mathrm{~Hz}, 1 \mathrm{H}), 3.40$ (d, $J=15.2$ $\mathrm{Hz}, 1 \mathrm{H}), 2.90(\mathrm{~d}, J=15.3 \mathrm{~Hz}, 1 \mathrm{H}), 2.77 \sim 2.62(\mathrm{~m}, 1 \mathrm{H})$, $2.34 \sim 2.22(\mathrm{~m}, 1 \mathrm{H}), 2.20(\mathrm{~d}, J=18.4 \mathrm{~Hz}, 1 \mathrm{H}), 2.08 \sim 1.87$ $(\mathrm{m}, 3 \mathrm{H}), 1.43 \sim 1.32(\mathrm{~m}, 1 \mathrm{H}), 0.92(\mathrm{~s}, 3 \mathrm{H}), 0.83(\mathrm{~s}, 3 \mathrm{H})$; ${ }^{13} \mathrm{C}$ NMR $\left(150 \mathrm{MHz}, \mathrm{CDCl}_{3}\right) \delta: 168.8,137.8,137.6,129.1$, 128.6, 128.0, 127.6, 125.5, 123.3, 75.4, 53.4, 51.0, 50.8, 43.1, 34.2, 30.7, 27.4, 19.6, 18.8. HRMS (ESI) calcd for $\mathrm{C}_{23} \mathrm{H}_{29} \mathrm{~N}_{2} \mathrm{O}_{3} \mathrm{~S}[\mathrm{M}+\mathrm{H}]^{+}: 413.1899$, found 413.1895.

(+)-1-(2-(Methoxyimino)-7,7-dimethylbicyclo[2.2.1]heptan-1-yl)- $N$-(3-methoxyphenyl)methanesulfonamide (4d): Yield 88\%, white solid, m.p. $68 \sim 70{ }^{\circ} \mathrm{C} ;[\alpha]_{\mathrm{D}}^{20}+$ 27.5 (c 1, $\left.\mathrm{CH}_{3} \mathrm{OH}\right) ;{ }^{1} \mathrm{H}$ NMR (400 MHz, $\mathrm{CDCl}_{3}$ ) $\delta: 8.70$ (bs, $1 \mathrm{H}), 7.23(\mathrm{t}, J=8.1 \mathrm{~Hz}, 1 \mathrm{H}), 6.92(\mathrm{t}, J=2.2 \mathrm{~Hz}, 1 \mathrm{H})$, $6.92 \sim 6.84(\mathrm{~m}, 1 \mathrm{H}), 6.79 \sim 6.71(\mathrm{~m}, 1 \mathrm{H}), 3.94(\mathrm{~s}, 3 \mathrm{H})$, $3.80(\mathrm{~s}, 3 \mathrm{H}), 3.47$ (d, $J=15.2 \mathrm{~Hz}, 1 \mathrm{H}), 2.94$ (d, $J=15.3$ $\mathrm{Hz}, 1 \mathrm{H}), 2.68 \sim 2.53(\mathrm{~m}, 1 \mathrm{H}), 2.32 \sim 2.18(\mathrm{~m}, 1 \mathrm{H}), 2.08 \sim$ $2.03(\mathrm{~m}, 1 \mathrm{H}), 2.02 \sim 1.85(\mathrm{~m}, 3 \mathrm{H}), 1.39 \sim 1.30(\mathrm{~m}, 1 \mathrm{H})$, $0.91(\mathrm{~s}, 3 \mathrm{H}), 0.83(\mathrm{~s}, 3 \mathrm{H}) ;{ }^{13} \mathrm{C} \mathrm{NMR}\left(100 \mathrm{~Hz}, \mathrm{CDCl}_{3}\right) \delta$ : 167.4, 159.8, 138.8, 129.4, 114.3, 110.8, 108.3, 61.0, 54.7,
52.6, 50.5, 50.4, 42.5, 33.2, 30.1, 26.8, 19.0, 18.3. HRMS (ESI) calcd for $\mathrm{C}_{18} \mathrm{H}_{27} \mathrm{~N}_{2} \mathrm{O}_{4} \mathrm{~S}[\mathrm{M}+\mathrm{H}]^{+}: 367.1692$, found 367.1692 .

(+)-1-(2-(Butoxyimino)-7,7-dimethylbicyclo[2.2.1]hept an-1-yl)- $N$-(3-methoxyphenyl)methanesulfonamide (4e): Yield 83\%, yellowish solid, m.p. 53 $54{ }^{\circ} \mathrm{C} ;[\alpha]_{\mathrm{D}}^{20}+23.3$ (c 1, $\left.\mathrm{CH}_{3} \mathrm{OH}\right) ;{ }^{1} \mathrm{H} \mathrm{NMR}\left(400 \mathrm{MHz}, \mathrm{CDCl}_{3}\right) \delta: 8.91$ (bs, $1 \mathrm{H}), 7.25$ (t, $J=8.1 \mathrm{~Hz}, 1 \mathrm{H}), 6.94(\mathrm{t}, J=2.3 \mathrm{~Hz}, 1 \mathrm{H}), 6.89$ (dd, $J=7.9,2.0 \mathrm{~Hz}, 1 \mathrm{H}), 6.77$ (dd, $J=8.3,2.5 \mathrm{~Hz}, 1 \mathrm{H})$, $4.22 \sim 4.07(\mathrm{~m}, 2 \mathrm{H}), 3.82(\mathrm{~s}, 3 \mathrm{H}), 3.50(\mathrm{~d}, J=15.2 \mathrm{~Hz}$, $1 \mathrm{H}), 2.96(\mathrm{~d}, J=15.2 \mathrm{~Hz}, 1 \mathrm{H}), 2.68 \sim 2.53(\mathrm{~m}, 1 \mathrm{H}), 2.32 \sim$ $2.21(\mathrm{~m}, 1 \mathrm{H}), 2.12(\mathrm{~d}, J=18.3 \mathrm{~Hz}, 1 \mathrm{H}), 2.07 \sim 1.98(\mathrm{~m}$, $1 \mathrm{H}), 1.99 \sim 1.87(\mathrm{~m}, 2 \mathrm{H}), 1.76-1.59(\mathrm{~m}, 2 \mathrm{H}), 1.48 \sim 1.33$ $(\mathrm{m}, 3 \mathrm{H}), 1.02 \sim 0.88(\mathrm{~m}, 6 \mathrm{H}), 0.86(\mathrm{~s}, 3 \mathrm{H}) ;{ }^{13} \mathrm{C}$ NMR $(100$ $\left.\mathrm{Hz}, \mathrm{CDCl}_{3}\right) \delta: 167.6,160.3,139.4,129.9,115.0,111.4$, 109.0, 73.7, 55.3, 53.2, 51.1, 51.0, 43.0, 33.9, 31.1, 30.7, 27.4, 19.6, 19.2, 18.8, 13.9. HRMS (ESI) calcd for $\mathrm{C}_{21} \mathrm{H}_{33} \mathrm{~N}_{2} \mathrm{O}_{4} \mathrm{~S}[\mathrm{M}+\mathrm{H}]^{+}:$409.2161, found 409.2159.

(+)-1-(2-((Benzyloxy)imino)-7,7-dimethylbicyclo[2.2.1]heptan-1-yl)- $N$-(3-methoxyphenyl)methanesulfonamide (4f): Yield $82 \%$, white solid, m.p. $84 \sim 85{ }^{\circ} \mathrm{C}$; $[\alpha]_{\mathrm{D}}^{20}+$ 20.6 (c 1, $\left.\mathrm{CH}_{3} \mathrm{OH}\right) ;{ }^{1} \mathrm{H}$ NMR $\left(400 \mathrm{MHz}, \mathrm{CDCl}_{3}\right) \delta: 8.45$ (s, $1 \mathrm{H}), 7.41 \sim 7.28(\mathrm{~m}, 4 \mathrm{H}), 7.30 \sim 7.22(\mathrm{~m}, 1 \mathrm{H}), 7.12(\mathrm{t}, J=$ $8.1 \mathrm{~Hz}, 1 \mathrm{H}), 6.80(\mathrm{t}, J=2.3 \mathrm{~Hz}, 1 \mathrm{H}), 6.77 \sim 6.69(\mathrm{~m}, 1 \mathrm{H})$, $6.59 \sim 6.51(\mathrm{~m}, 1 \mathrm{H}), 5.15(\mathrm{dd}, J=27.3,12.4 \mathrm{~Hz}, 2 \mathrm{H}), 3.78$ $(\mathrm{s}, 3 \mathrm{H}), 3.46(\mathrm{~d}, J=15.3 \mathrm{~Hz}, 1 \mathrm{H}), 2.92(\mathrm{~d}, J=15.3 \mathrm{~Hz}$, $1 \mathrm{H}), 2.75 \sim 2.62(\mathrm{~m}, 1 \mathrm{H}), 2.33 \sim 2.21(\mathrm{~m}, 1 \mathrm{H}), 2.18(\mathrm{~d}, J=$ $18.3 \mathrm{~Hz}, 1 \mathrm{H}), 2.09 \sim 2.00(\mathrm{~m}, 1 \mathrm{H}), 2.00 \sim 1.87(\mathrm{~m}, 2 \mathrm{H})$, $1.42 \sim 1.33(\mathrm{~m}, 1 \mathrm{H}), 0.92(\mathrm{~s}, 3 \mathrm{H}), 0.83(\mathrm{~s}, 3 \mathrm{H}) ;{ }^{13} \mathrm{C} \mathrm{NMR}$ $\left(100 \mathrm{MHz}, \mathrm{CDCl}_{3}\right) \delta: 168.7,160.1,139.1,137.4,129.7$, $128.6,128.0,127.8,115.2,111.5,109.2,75.5,55.3,53.4$, 51.0, 50.8, 43.0, 34.2, 30.7, 27.4, 19.6, 18.8. HRMS (ESI) calcd for $\mathrm{C}_{24} \mathrm{H}_{31} \mathrm{~N}_{2} \mathrm{O}_{4} \mathrm{~S}[\mathrm{M}+\mathrm{H}]^{+}$: 443.2005, found 443.2002 .

(+)-N-(3-Chlorophenyl)-1-(2-(methoxyimino)-7,7-dimethylbicyclo [2.2.1] heptan-1-yl)methanesulfonamide (4g): Yield 83\%, white solid, m.p. 108 109 ${ }^{\circ} \mathrm{C}$; $[\alpha]_{\mathrm{D}}^{20}+$ 21.4 (c 1, $\left.\mathrm{CH}_{3} \mathrm{OH}\right) ;{ }^{1} \mathrm{H} \mathrm{NMR}\left(400 \mathrm{MHz}, \mathrm{DMSO}-d_{6}\right) \delta$ : $10.15(\mathrm{~s}, 1 \mathrm{H}), 7.35(\mathrm{t}, J=8.1 \mathrm{~Hz}, 1 \mathrm{H}), 7.30(\mathrm{t}, J=2.1 \mathrm{~Hz}$, $1 \mathrm{H}), 7.22(\mathrm{dd}, J=8.0,2.1 \mathrm{~Hz}, 1 \mathrm{H}), 7.11(\mathrm{dd}, J=7.9,2.0$ $\mathrm{Hz}, 1 \mathrm{H}), 3.66$ (s, 3H), 3.62 (d, $J=15.0 \mathrm{~Hz}, 1 \mathrm{H}), 3.12$ (d, $J=14.9 \mathrm{~Hz}, 1 \mathrm{H}), 2.44 \sim 2.31(\mathrm{~m}, 2 \mathrm{H}), 1.92(\mathrm{~d}, J=17.8 \mathrm{~Hz}$, $1 \mathrm{H}), 1.90 \sim 1.80(\mathrm{~m}, 2 \mathrm{H}), 1.71 \sim 1.58(\mathrm{~m}, 1 \mathrm{H}), 1.34 \sim 1.20$ $(\mathrm{m}, 1 \mathrm{H}), 0.96(\mathrm{~s}, 3 \mathrm{H}), 0.72(\mathrm{~s}, 3 \mathrm{H}) ;{ }^{13} \mathrm{C} \mathrm{NMR}(100 \mathrm{MHz}$, $\left.\mathrm{CDCl}_{3}\right) \delta: 168.2,139.4,134.9,130.3,125.6,122.7,120.6$, 61.6, 53.2, 51.5, 51.1, 43.0, 33.8, 30.6, 27.3, 19.6, 18.8 . HRMS (ESI) calcd for $\mathrm{C}_{17} \mathrm{H}_{24} \mathrm{ClN}_{2} \mathrm{O}_{3} \mathrm{~S}[\mathrm{M}+\mathrm{H}]^{+}$: 371.1196, found 371.1199.

(+)-1-(2-(Butoxyimino)-7,7-dimethylbicyclo[2.2.1]heptan-1-yl)- $N$-(3-chlorophenyl)methanesulfonamide (4h): Yield 87\%, white solid, m.p. 71 $72{ }^{\circ} \mathrm{C} ;[\alpha]_{\mathrm{D}}^{20}+18.9(c$ $\left.1, \mathrm{CH}_{3} \mathrm{OH}\right) ;{ }^{1} \mathrm{H}$ NMR (600 MHz, $\left.\mathrm{CDCl}_{3}\right) \delta: 9.06$ (bs, $\left.1 \mathrm{H}\right)$, $7.36 \sim 7.33(\mathrm{~m}, 1 \mathrm{H}), 7.30(\mathrm{~d}, J=0.9 \mathrm{~Hz}, 1 \mathrm{H}), 7.22 \sim 7.17$ $(\mathrm{m}, 2 \mathrm{H}), 4.19 \sim 4.09(\mathrm{~m}, 2 \mathrm{H}), 3.45(\mathrm{~d}, J=15.3 \mathrm{~Hz}, 1 \mathrm{H})$, $2.99(\mathrm{~d}, J=15.3 \mathrm{~Hz}, 1 \mathrm{H}), 2.67 \sim 2.58(\mathrm{~m}, 1 \mathrm{H}), 2.27 \sim 2.21$ (m, $1 \mathrm{H}), 2.12(\mathrm{~d}, J=18.3 \mathrm{~Hz}, 1 \mathrm{H}), 2.07 \sim 2.02(\mathrm{~m}, 1 \mathrm{H})$, $1.99 \sim 1.93(\mathrm{~m}, 2 \mathrm{H}), 1.70 \sim 1.64(\mathrm{~m}, 2 \mathrm{H}), 1.46 \sim 1.36(\mathrm{~m}$, 
$3 \mathrm{H}), 0.98 \sim 0.92(\mathrm{~m}, 6 \mathrm{H}), 0.86(\mathrm{~s}, 3 \mathrm{H}) ;{ }^{13} \mathrm{C} \mathrm{NMR}(150$ $\left.\mathrm{MHz}, \mathrm{CDCl}_{3}\right) \delta: 167.9,139.5,134.9,130.3,125.6,122.8$, 120.8, 73.8, 53.2, 51.6, 51.1, 43.1, 34.0, 31.2, 30.7, 27.4, 19.6, 19.2, 18.8, 13.9. HRMS (ESI) calcd for $\mathrm{C}_{20} \mathrm{H}_{30} \mathrm{ClN}_{2-}$ $\mathrm{O}_{3} \mathrm{~S}[\mathrm{M}+\mathrm{H}]^{+}:$413.1666, found 413.1665.

(+)-1-(2-((Benzyloxy)imino)-7,7-dimethylbicyclo[2.2.1]heptan-1-yl)- $N$-(3-chlorophenyl)methanesulfonamide (4i): Yield 88\%, white solid, m.p. 107 $109{ }^{\circ} \mathrm{C}$; $[\alpha]_{\mathrm{D}}^{20}+19.5$ (c 1, $\left.\mathrm{CH}_{3} \mathrm{OH}\right) ;{ }^{1} \mathrm{H}$ NMR $\left(600 \mathrm{MHz}, \mathrm{CDCl}_{3}\right) \delta: 8.52$ (bs, $1 \mathrm{H}), 7.38 \sim 7.33(\mathrm{~m}, 2 \mathrm{H}), 7.31(\mathrm{t}, J=7.6 \mathrm{~Hz}, 2 \mathrm{H}), 7.27 \sim$ $7.22(\mathrm{~m}, 1 \mathrm{H}), 7.14 \sim 7.11(\mathrm{~m}, 2 \mathrm{H}), 7.02(\mathrm{t}, J=1.8 \mathrm{~Hz}, 1 \mathrm{H})$, $6.86 \sim 6.80(\mathrm{~m}, 1 \mathrm{H}), 5.18(\mathrm{~d}, J=12.6 \mathrm{~Hz}, 1 \mathrm{H}), 5.11(\mathrm{~d}, J=$ $12.7 \mathrm{~Hz}, 1 \mathrm{H}), 3.36(\mathrm{~d}, J=15.3 \mathrm{~Hz}, 1 \mathrm{H}), 2.92$ (d, $J=15.3$ $\mathrm{Hz}, 1 \mathrm{H}), 2.74 \sim 2.65(\mathrm{~m}, 1 \mathrm{H}), 2.27 \sim 2.22(\mathrm{~m}, 1 \mathrm{H}), 2.20(\mathrm{~d}$, $J=18.4 \mathrm{~Hz}, 1 \mathrm{H}), 1.99(\mathrm{t}, J=4.6 \mathrm{~Hz}, 1 \mathrm{H}), 1.95 \sim 1.91(\mathrm{~m}$, $1 \mathrm{H}), 1.53(\mathrm{~s}, 1 \mathrm{H}), 1.41 \sim 1.35(\mathrm{~m}, 1 \mathrm{H}), 0.92(\mathrm{~s}, 3 \mathrm{H}), 0.83$ $(\mathrm{s}, 3 \mathrm{H}) ;{ }^{13} \mathrm{C} \mathrm{NMR}\left(150 \mathrm{MHz}, \mathrm{CDCl}_{3}\right) \delta: 169.0,139.0$, $137.5,134.5,130.0,128.6,128.1,127.6,125.6,123.2$, 121.2, 75.4, 53.4, 51.2, 51.0, 43.0, 34.2, 30.8, 27.4, 19.5, 18.8. HRMS (ESI) calcd for $\mathrm{C}_{23} \mathrm{H}_{28} \mathrm{ClN}_{2} \mathrm{O}_{3} \mathrm{~S}[\mathrm{M}+\mathrm{H}]^{+}$: 447.1509, found 447.1514.

(+)-1-(2-(Methoxyimino)-7,7-dimethylbicyclo[2.2.1]heptan-1-yl)- $N$-(4-methoxyphenyl)methanesulfonamide (4j): Yield 83\%, yellowish solid, m.p. $103 \sim 104{ }^{\circ} \mathrm{C}$; $[\alpha]_{\mathrm{D}}^{20}+43.1\left(c 1, \mathrm{CH}_{3} \mathrm{OH}\right) ;{ }^{1} \mathrm{H}$ NMR $\left(400 \mathrm{MHz} \mathrm{CDCl}_{3}\right) \delta$ : $8.67(\mathrm{~s}, 1 \mathrm{H}), 7.30 \sim 7.26(\mathrm{~m}, 2 \mathrm{H}), 6.88(\mathrm{~d}, J=8.8 \mathrm{~Hz}, 2 \mathrm{H})$, $3.92(\mathrm{~s}, 3 \mathrm{H}), 3.80$ (s, 3H), $3.43(\mathrm{~d}, J=15.3 \mathrm{~Hz}, 1 \mathrm{H}), 2.87$ $(\mathrm{d}, J=15.2 \mathrm{~Hz}, 1 \mathrm{H}), 2.66 \sim 2.53(\mathrm{~m}, 1 \mathrm{H}), 2.31 \sim 2.22(\mathrm{~m}$, $1 \mathrm{H}), 2.09$ (d, $J=18.2 \mathrm{~Hz}, 1 \mathrm{H}), 2.04 \sim 1.87(\mathrm{~m}, 3 \mathrm{H}), 1.39 \sim$ $1.31(\mathrm{~m}, 1 \mathrm{H}), 0.91(\mathrm{~s}, 3 \mathrm{H}), 0.85(\mathrm{~s}, 3 \mathrm{H}) ;{ }^{13} \mathrm{C}$ NMR $(100$ $\left.\mathrm{MHz}, \mathrm{CDCl}_{3}\right) \delta: 168.0,157.9,131.0,125.5,114.5,61.5$, 55.4, 53.2, 51.1, 50.2, 43.0, 33.8, 30.8, 27.4, 19.6, 18.8 . HRMS (ESI) calcd for $\mathrm{C}_{18} \mathrm{H}_{27} \mathrm{~N}_{2} \mathrm{O}_{4} \mathrm{~S}[\mathrm{M}+\mathrm{H}]^{+}: 367.1692$, found 367.1693 .

(+)-1-(2-(Butoxyimino)-7,7-dimethylbicyclo[2.2.1]heptan-1-yl)- $N$-(4-methoxyphenyl)methanesulfonamide (4k): Yield $86 \%$, yellow gum; $[\alpha]_{\mathrm{D}}^{20}+32.3\left(c 1, \mathrm{CH}_{3} \mathrm{OH}\right) ;{ }^{1} \mathrm{H}$ NMR $\left(400 \mathrm{MHz}, \mathrm{CDCl}_{3}\right) \delta: 8.79(\mathrm{~s}, 1 \mathrm{H}), 7.33 \sim 7.27(\mathrm{~m}$, $2 \mathrm{H}), 6.96 \sim 6.83(\mathrm{~m}, 2 \mathrm{H}), 4.21 \sim 4.03(\mathrm{~m}, 2 \mathrm{H}), 3.82(\mathrm{~s}$, $3 \mathrm{H}), 3.46(\mathrm{~d}, J=15.3 \mathrm{~Hz}, 1 \mathrm{H}), 2.89$ (d, $J=15.3 \mathrm{~Hz}, 1 \mathrm{H})$, $2.68 \sim 2.57(\mathrm{~m}, 1 \mathrm{H}), 2.36 \sim 2.22(\mathrm{~m}, 1 \mathrm{H}), 2.12(\mathrm{~d}, J=18.3$ $\mathrm{Hz}, 1 \mathrm{H}), 2.02 \sim 1.94(\mathrm{~m}, 3 \mathrm{H}), 1.72 \sim 1.60(\mathrm{~m}, 2 \mathrm{H}), 1.48 \sim$ $1.35(\mathrm{~m}, 3 \mathrm{H}), 1.00 \sim 0.87(\mathrm{~m}, 6 \mathrm{H}), 0.87(\mathrm{~s}, 3 \mathrm{H}) ;{ }^{13} \mathrm{C}$ NMR $\left(100 \mathrm{~Hz}, \mathrm{CDCl}_{3}\right) \delta: 167.7,157.9,131.0,125.6,114.5,73.7$, $55.4,53.3,51.0,50.3,43.0,33.9,31.1,30.8,27.4,19.6$, 19.1, 18.8, 13.9. HRMS (ESI) calcd for $\mathrm{C}_{21} \mathrm{H}_{33} \mathrm{~N}_{2} \mathrm{O}_{4} \mathrm{~S}$ $[\mathrm{M}+\mathrm{H}]^{+}:$409.2161, found 409.2156.

(+)-1-(2-((Benzyloxy)imino)-7,7-dimethylbicyclo[2.2.1]heptan-1-yl)- $N$-(4-methoxyphenyl)methanesulfonamide (4I): Yield 85\%, yellow gum; $[\alpha]_{\mathrm{D}}^{20}+33.2\left(c 1, \mathrm{CH}_{3} \mathrm{OH}\right)$; ${ }^{1} \mathrm{H}$ NMR (400 MHz, $\left.\mathrm{CDCl}_{3}\right) \delta: 8.27(\mathrm{~s}, 1 \mathrm{H}), 7.38 \sim 7.27$ $(\mathrm{m}, 4 \mathrm{H}), 7.30 \sim 7.21(\mathrm{~m}, 1 \mathrm{H}), 6.99 \sim 6.90(\mathrm{~m}, 2 \mathrm{H}), 6.78 \sim$ $6.71(\mathrm{~m}, 2 \mathrm{H}), 5.14(\mathrm{dd}, J=29.4,12.7 \mathrm{~Hz}, 2 \mathrm{H}), 3.79$ (s, $3 \mathrm{H}), 3.38$ (d, $J=15.3 \mathrm{~Hz}, 1 \mathrm{H}), 2.83$ (d, $J=15.3 \mathrm{~Hz}, 1 \mathrm{H})$, $2.76 \sim 2.66(\mathrm{~m}, 1 \mathrm{H}), 2.33 \sim 2.25(\mathrm{~m}, 1 \mathrm{H}), 2.20(\mathrm{~d}, J=18.3$ $\mathrm{Hz}, 1 \mathrm{H}), 2.06 \sim 1.90(\mathrm{~m}, 3 \mathrm{H}), 1.43 \sim 1.32(\mathrm{~m}, 1 \mathrm{H}), 0.91(\mathrm{~s}$, $3 \mathrm{H}), 0.85(\mathrm{~s}, 3 \mathrm{H}) ;{ }^{13} \mathrm{C} \mathrm{NMR}\left(100 \mathrm{~Hz}, \mathrm{CDCl}_{3}\right) \delta: 168.9$,
$157.7,137.6,130.6,128.6,128.0,127.5,125.7,114.3$, 75.3, 55.4, 53.5, 51.0, 50.1, 43.0, 34.2, 30.9, 27.4, 19.6, 18.8. HRMS (ESI) calcd for $\mathrm{C}_{24} \mathrm{H}_{31} \mathrm{~N}_{2} \mathrm{O}_{4} \mathrm{~S}[\mathrm{M}+\mathrm{H}]^{+}$: 443.2005, found 443.2001.

(+)-N-(4-Chlorophenyl)-1-(2-(methoxyimino)-7,7-dimethylbicyclo[2.2.1] heptan-1-yl)methanesulfonamide (4m): Yield 84\%, white solid, m.p. 89 90 ${ }^{\circ} \mathrm{C} ;[\alpha]_{\mathrm{D}}^{20}+$ 29.2 (c 1, $\left.\mathrm{CH}_{3} \mathrm{OH}\right) ;{ }^{1} \mathrm{H} \mathrm{NMR}\left(400 \mathrm{MHz}, \mathrm{DMSO}-d_{6}\right) \delta$ : $10.15(\mathrm{~s}, 1 \mathrm{H}), 7.35(\mathrm{t}, J=8.1 \mathrm{~Hz}, 1 \mathrm{H}), 7.30(\mathrm{t}, J=2.1 \mathrm{~Hz}$, $1 \mathrm{H}), 7.25 \sim 7.19(\mathrm{~m}, 1 \mathrm{H}), 7.14 \sim 7.07(\mathrm{~m}, 1 \mathrm{H}), 3.66(\mathrm{~s}$, $3 \mathrm{H}), 3.62(\mathrm{~d}, J=15.0 \mathrm{~Hz}, 1 \mathrm{H}), 3.12(\mathrm{~d}, J=14.9 \mathrm{~Hz}, 1 \mathrm{H})$, $2.46 \sim 2.24(\mathrm{~m}, 2 \mathrm{H}), 1.92(\mathrm{~d}, J=17.8 \mathrm{~Hz}, 1 \mathrm{H}), 1.90 \sim 1.79$ $(\mathrm{m}, 2 \mathrm{H}), 1.72 \sim 1.58(\mathrm{~m}, 1 \mathrm{H}), 1.36 \sim 1.20(\mathrm{~m}, 1 \mathrm{H}), 0.96(\mathrm{~s}$, $3 \mathrm{H}), 0.72(\mathrm{~s}, 3 \mathrm{H}) ;{ }^{13} \mathrm{C}$ NMR $\left(100 \mathrm{MHz}, \mathrm{CDCl}_{3}\right) \delta: 168.2$, $136.8,131.2,129.4,124.3,61.5,53.2,51.2,43.0,33.8$, 30.6, 27.3, 19.6, 18.8. HRMS (ESI) calcd for $\mathrm{C}_{17} \mathrm{H}_{24} \mathrm{ClN}_{2^{-}}$ $\mathrm{O}_{3} \mathrm{~S}[\mathrm{M}+\mathrm{H}]^{+}:$371.1196, found 371.1195.

(+)-1-(2-(Butoxyimino)-7,7-dimethylbicyclo[2.2.1]heptan-1-yl)- $N$-(4-chlorophenyl)methanesulfonamide (4n): Yield $79 \%$, white solid, m.p. $64 \sim 66{ }^{\circ} \mathrm{C} ;[\alpha]_{\mathrm{D}}^{20}+23.6(c$ $\left.1, \mathrm{CH}_{3} \mathrm{OH}\right) ;{ }^{1} \mathrm{H}$ NMR (400 MHz, $\left.\mathrm{CDCl}_{3}\right) \delta: 9.04(\mathrm{~s}, 1 \mathrm{H})$, $7.38 \sim 7.29(\mathrm{~m}, 2 \mathrm{H}), 7.28 \sim 7.25(\mathrm{~m}, 2 \mathrm{H}), 4.21 \sim 4.06(\mathrm{~m}$, 2H), $3.41(\mathrm{~d}, J=15.3 \mathrm{~Hz}, 1 \mathrm{H}), 2.95(\mathrm{~d}, J=15.3 \mathrm{~Hz}, 1 \mathrm{H})$, $2.69 \sim 2.56(\mathrm{~m}, 1 \mathrm{H}), 2.32 \sim 2.20(\mathrm{~m}, 1 \mathrm{H}), 2.12(\mathrm{~d}, J=18.3$ $\mathrm{Hz}, 1 \mathrm{H}), 2.07 \sim 2.00(\mathrm{~m}, 1 \mathrm{H}), 2.02 \sim 1.89(\mathrm{~m}, 2 \mathrm{H}), 1.73 \sim$ $1.58(\mathrm{~m}, 2 \mathrm{H}), 1.48 \sim 1.32(\mathrm{~m}, 3 \mathrm{H}), 0.98 \sim 0.91(\mathrm{~m}, 6 \mathrm{H})$, $0.86(\mathrm{~s}, 3 \mathrm{H}) ;{ }^{13} \mathrm{C}$ NMR $\left(100 \mathrm{MHz}, \mathrm{CDCl}_{3}\right) \delta: 167.9,136.8$, 131.3, 129.4, 124.4, 73.7, 53.2, 51.2, 51.1, 43.0, 33.9, 31.1, 30.7, 27.4, 19.6, 19.1, 18.8, 13.9. HRMS (ESI) calcd for $\mathrm{C}_{20} \mathrm{H}_{30} \mathrm{ClN}_{2} \mathrm{O}_{3} \mathrm{~S}[\mathrm{M}+\mathrm{H}]^{+}:$413.1666, found 413.1668.

(+)-1-(2-((Benzyloxy)imino)-7,7-dimethylbicyclo[2.2.1]heptan-1-yl)- $N$-(4-chlorophenyl)methanesulfonamide (40): Yield 85\%, white gum; $\left.[\alpha]_{\mathrm{D}}^{20}+22.9(c), \mathrm{CH}_{3} \mathrm{OH}\right) ;{ }^{1} \mathrm{H}$ NMR (400 MHz, $\left.\mathrm{CDCl}_{3}\right) \delta: 8.47(\mathrm{~s}, 1 \mathrm{H}), 7.36 \sim 7.27(\mathrm{~m}$, $5 \mathrm{H}), 7.19 \sim 7.11(\mathrm{~m}, 2 \mathrm{H}), 6.90 \sim 6.83(\mathrm{~m}, 2 \mathrm{H}), 5.14(\mathrm{dd}, J$ $=30.9,12.9 \mathrm{~Hz}, 2 \mathrm{H}), 3.31(\mathrm{~d}, J=15.4 \mathrm{~Hz}, 1 \mathrm{H}), 2.89$ (d, $J$ $=15.4 \mathrm{~Hz}, 1 \mathrm{H}), 2.76 \sim 2.65(\mathrm{~m}, 1 \mathrm{H}), 2.33 \sim 2.25(\mathrm{~m}, 1 \mathrm{H})$, $2.21(\mathrm{~d}, J=18.5 \mathrm{~Hz}, 1 \mathrm{H}), 2.03 \sim 1.93(\mathrm{~m}, 3 \mathrm{H}), 1.44 \sim 1.34$ (m, 1H), $0.92(\mathrm{~s}, 3 \mathrm{H}), 0.83(\mathrm{~s}, 3 \mathrm{H}) ;{ }^{13} \mathrm{C}$ NMR (100 MHz, $\left.\mathrm{CDCl}_{3}\right) \delta: 169.1,137.7,136.4,131.1,129.1,128.7,128.1$, $127.5,124.6,75.3,53.5,51.0,50.9,43.0,34.2,30.8,27.4$, 19.6, 18.8. HRMS (ESI) calcd for $\mathrm{C}_{23} \mathrm{H}_{28} \mathrm{ClN}_{2} \mathrm{O}_{3} \mathrm{~S}[\mathrm{M}+$ $\mathrm{H}]^{+}:$447.1509, found 447.1507.

(+)-1-(2-(Methoxyimino)-7,7-dimethylbicyclo[2.2.1]heptan-1-yl)- $N$-(3-(trifluoromethyl)phenyl)methanesulfonamide (4p): Yield 80\%, white solid, m.p. $81 \sim 83{ }^{\circ} \mathrm{C}$; $[\alpha]_{\mathrm{D}}^{20}+20.5\left(c 1, \mathrm{CH}_{3} \mathrm{OH}\right) ;{ }^{1} \mathrm{H}$ NMR $\left(400 \mathrm{MHz}, \mathrm{CDCl}_{3}\right) \delta$ : $9.12(\mathrm{~s}, 1 \mathrm{H}), 7.56(\mathrm{~s}, 1 \mathrm{H}), 7.55 \sim 7.51(\mathrm{~m}, 1 \mathrm{H}), 7.50 \sim 7.43$ (m, 2H), $3.93(\mathrm{~s}, 3 \mathrm{H}), 3.40(\mathrm{~d}, J=15.3 \mathrm{~Hz}, 1 \mathrm{H}), 2.98(\mathrm{~d}$, $J=15.3 \mathrm{~Hz}, 1 \mathrm{H}), 2.69 \sim 2.52(\mathrm{~m}, 1 \mathrm{H}), 2.31 \sim 2.17(\mathrm{~m}, 1 \mathrm{H})$, $2.10(\mathrm{~d}, J=18.4 \mathrm{~Hz}, 1 \mathrm{H}), 2.00 \sim 1.88(\mathrm{~m}, 3 \mathrm{H}), 1.40 \sim 1.32$ $(\mathrm{m}, 1 \mathrm{H}), 0.92(\mathrm{~s}, 3 \mathrm{H}), 0.82(\mathrm{~s}, 3 \mathrm{H}) ;{ }^{13} \mathrm{C}$ NMR $(150 \mathrm{MHz}$, $\left.\mathrm{CDCl}_{3}\right) \delta: 168.4,138.9,131.7(\mathrm{q}, J=32.6 \mathrm{~Hz}), 130.0$, $126.0,123.7$ (q, $J=272.4 \mathrm{~Hz}), 122.1$ (q, $J=3.8 \mathrm{~Hz}$ ), 119.2 (q, $J=3.9 \mathrm{~Hz}), 61.5,53.2,51.6,51.2,43.0,33.9,30.6$, 27.4, 19.5, 18.8. HR-MS (ESI) calcd for $\mathrm{C}_{18} \mathrm{H}_{24} \mathrm{~F}_{3} \mathrm{~N}_{2} \mathrm{O}_{3} \mathrm{~S}$ $[\mathrm{M}+\mathrm{H}]^{+}:$405.1460, found 405.1461. 
$(+)-1-(2-(B u t o x y i m i n o)-7,7-d i m e t h y l b i c y c l o[2.2 .1]$ heptan-1-yl)- $N$-(3-(trifluoromethyl)phenyl)methanesulfonamide (4q): Yield 79\%, white solid, m.p. 72 $73{ }^{\circ} \mathrm{C} ;[\alpha]_{\mathrm{D}}^{20}+$ 22.4 (c 1, $\left.\mathrm{CH}_{3} \mathrm{OH}\right) ;{ }^{1} \mathrm{H} \mathrm{NMR}\left(400 \mathrm{MHz}, \mathrm{CDCl}_{3}\right) \delta: 9.22$ (bs, $1 \mathrm{H}), 7.60 \sim 7.52(\mathrm{~m}, 2 \mathrm{H}), 7.52 \sim 7.44(\mathrm{~m}, 2 \mathrm{H}), 4.26 \sim$ $4.07(\mathrm{~m}, 2 \mathrm{H}), 3.43(\mathrm{~d}, J=15.3 \mathrm{~Hz}, 1 \mathrm{H}), 3.01(\mathrm{~d}, J=15.3$ $\mathrm{Hz}, 1 \mathrm{H}), 2.72 \sim 2.57(\mathrm{~m}, 1 \mathrm{H}), 2.31 \sim 2.20(\mathrm{~m}, 1 \mathrm{H}), 2.14(\mathrm{~d}$, $J=18.4 \mathrm{~Hz}, 1 \mathrm{H}), 2.10 \sim 2.00(\mathrm{~m}, 1 \mathrm{H}), 2.00 \sim 1.89(\mathrm{~m}, 2 \mathrm{H})$, $1.74 \sim 1.60(\mathrm{~m}, 2 \mathrm{H}), 1.47 \sim 1.36(\mathrm{~m}, 3 \mathrm{H}), 0.99 \sim 0.91(\mathrm{~m}$, $6 \mathrm{H}), 0.86(\mathrm{~s}, 3 \mathrm{H}) ;{ }^{13} \mathrm{C}$ NMR $\left(150 \mathrm{MHz}, \mathrm{CDCl}_{3}\right) \delta: 168.2$, $138.9,131.7$ (q, $J=32.6 \mathrm{~Hz}), 129.9,126.2,123.6$ (q, $J=$ $272.5 \mathrm{~Hz}), 122.1(\mathrm{q}, J=3.8 \mathrm{~Hz}), 119.3(\mathrm{q}, J=3.9 \mathrm{~Hz})$, 73.8, 53.2, 51.7, 51.1, 43.0, 34.0, 31.1, 30.7, 27.4, 19.5, 19.2, 18.8, 13.8. HR-MS (ESI) calcd for $\mathrm{C}_{21} \mathrm{H}_{30} \mathrm{~F}_{3} \mathrm{~N}_{2} \mathrm{O}_{3} \mathrm{~S}$ $[\mathrm{M}+\mathrm{H}]^{+}:$447.1929, found 447.1933.

(+)-1-(2-((Benzyloxy)imino)-7,7-dimethylbicyclo[2.2.1]heptan-1-yl)- $N$-(3-(trifluoromethyl)phenyl)methanesulfonamide (4r): Yield $82 \%$, white solid, m.p. $121 \sim 122{ }^{\circ} \mathrm{C}$; $[\alpha]_{\mathrm{D}}^{20}+18.6\left(c 1, \mathrm{CH}_{3} \mathrm{OH}\right) ;{ }^{1} \mathrm{H} \mathrm{NMR}\left(400 \mathrm{MHz}, \mathrm{CDCl}_{3}\right) \delta$ : 8.63 (bs, $1 \mathrm{H}), 7.45 \sim 7.40(\mathrm{~m}, 1 \mathrm{H}), 7.39 \sim 7.34(\mathrm{~m}, 2 \mathrm{H})$, $7.34 \sim 7.30(\mathrm{~m}, 2 \mathrm{H}), 7.29(\mathrm{~s}, 1 \mathrm{H}), 7.27(\mathrm{~s}, 1 \mathrm{H}), 7.25 \sim 7.19$ $(\mathrm{m}, 1 \mathrm{H}), 7.15 \sim 7.10(\mathrm{~m}, 1 \mathrm{H}), 5.19(\mathrm{~d}, J=12.6 \mathrm{~Hz}, 1 \mathrm{H})$, $5.12(\mathrm{~d}, J=12.6 \mathrm{~Hz}, 1 \mathrm{H}), 3.33$ (d, $J=15.4 \mathrm{~Hz}, 1 \mathrm{H}), 2.93$ $(\mathrm{d}, J=15.3 \mathrm{~Hz}, 1 \mathrm{H}), 2.78 \sim 2.66(\mathrm{~m}, 1 \mathrm{H}), 2.32 \sim 2.16(\mathrm{~m}$, 2H), $2.09 \sim 1.96(\mathrm{~m}, 2 \mathrm{H}), 1.97 \sim 1.89(\mathrm{~m}, 1 \mathrm{H}), 1.43 \sim 1.35$ $(\mathrm{m}, 1 \mathrm{H}), 0.92(\mathrm{~s}, 3 \mathrm{H}), 0.83(\mathrm{~s}, 3 \mathrm{H}) ;{ }^{13} \mathrm{C}$ NMR $(150 \mathrm{~Hz}$, $\left.\mathrm{CDCl}_{3}\right) \delta: 169.3,138.5,137.5,131.5$ (q, $\left.J=32.6 \mathrm{~Hz}\right)$, 129.7, 128.7, 128.2, 127.7, 126.6, 123.6 (q, $J=272.6 \mathrm{~Hz})$, 122.2 (q, $J=3.8 \mathrm{~Hz}), 120.0(\mathrm{q}, J=3.8 \mathrm{~Hz}), 75.5,53.5$, 51.3, 51.1, 43.1, 34.3, 30.8, 27.4, 19.5, 18.8. HR-MS (ESI) calcd for $\mathrm{C}_{24} \mathrm{H}_{28} \mathrm{~F}_{3} \mathrm{~N}_{2} \mathrm{O}_{3} \mathrm{~S}[\mathrm{M}+\mathrm{H}]^{+}:$481.1773, found 481.1772 .

\subsection{Biological assays}

\subsubsection{Antitumor activity}

Antitumor activity of target compounds was measured using 3-(4,5-dimethylthiazol-2-yl)-2,5-diphenyltetrazolium bromide (MTT) assay against three cancer cell lines (A549, Hela, MCF-7 cells) and human normal hepatocytes (LO2) from the Cell Bank of the Chinese Academy of Sciences. Above cell lines were incubated in dulbecco's modified eagle medium (DMEM) supplemented with 10\% fetal bovine serum (FBS) in an incubator at $37{ }^{\circ} \mathrm{C}$ and $5 \%$ $\mathrm{CO}_{2}$. Then, cells were seeded onto 96-well plates with a density of $8 \times 10^{3}$ cells per well when they were at $\log$ phase of growth. After $24 \mathrm{~h}$, different concentrations $\left(50.00,25.00,12.50,6.25,3.13,1.55 \mu \mathrm{mol} \cdot \mathrm{L}^{-1}\right)$ of the synthesized compounds and positive control etoposide were added in cultures with serum-free medium for another $48 \mathrm{~h}$. Next, $10 \mu \mathrm{L}$ of solution of MTT $(5 \mathrm{mg} / \mathrm{mL})$ was added to each well and then cells were treated for $4 \mathrm{~h}$. Subsequently, the formed blue formazan crystals were dissolved by adding $100 \mu \mathrm{L}$ of dimethylsulfoxide (DMSO). Finally, the optical density of each well was measured with an enzyme-labeled instrument at $540 \mathrm{~nm}$ wavelength. The results were expressed as $\mathrm{IC}_{50}$ values which were calculated from the concentration- response curves by non-linear regression analysis.

\subsubsection{Cell cycle assay}

MCF-7 cells were added to 6-well plates and incubated overnight. Then, cells were treated with compound $\mathbf{4 r}$ at different concentrations $\left(0,2.5,5\right.$, and $10 \mu \mathrm{mol} \cdot \mathrm{L}^{-1}$, respectively) in DMEM medium, supplemented with $10 \%$ FBS for $24 \mathrm{~h}$. Afterwards, cells were washed with phosphate buffered saline (PBS), collected by centrifugation and fixed in the dark with ice cold ethanol at $-4{ }^{\circ} \mathrm{C}$. The fixed cells were then re-suspended with $0.1 \mathrm{mg} / \mathrm{mL}$ RNase stained with $40 \mathrm{mg} / \mathrm{mL}$ propidium iodide (PI). After incubation at $37{ }^{\circ} \mathrm{C}$ for $30 \mathrm{~min}$, all samples were analyzed for DNA content by flow cytometry (BD FACS Canto II).

\subsubsection{Cell apoptosis assay}

MCF-7 cells were seeded into 6-well plates and incubated for $24 \mathrm{~h}$ before treatment. Cells were then exposed to compound $4 \mathbf{r}$ at different concentrations $(0,2.5,5$ and 10 $\mu \mathrm{mol} \cdot \mathrm{L}^{-1}$, respectively). After treatment for $24 \mathrm{~h}$, cells were harvested and washed twice with PBS and then treated with Annexin V-FITC/PI at room temperature for $15 \mathrm{~min}$ in the dark. The subsequent flow cytometry system (BD Accuri C6) were used to examine the stained cells.

\subsubsection{Hoechst dye test}

Hoechst 33258 dye can provide a chance to differentiate dead cells from living ones by interpreting nucleus morphology. Cells were seeded into 6-well plates and incubated with compound $\mathbf{4 r}$ at the concentrations of $0,2.5,5$ and $10 \mu \mathrm{mol} \cdot \mathrm{L}^{-1}$ for $24 \mathrm{~h}$. After incubation, the medium was discarded, cells were washed by PBS, and then fixed in $4 \%$ paraformaldehyde for $10 \mathrm{~min}$. After fixation, cells were stained with $0.5 \mathrm{~mL}$ of Hoechst 33258 for $10 \mathrm{~min}$ at room temperature in a dark condition, then PBS washed twice. The stained nuclei were imaged at confocal microscopy (LSM710) with excitation wavelength at $350 \mathrm{~nm}$ and emission wavelength at $460 \mathrm{~nm}$.

\subsubsection{Reactive oxygen species (ROS) detection}

DCFH-DA is a fluorescent probe that is used to measure the changes in intracellular ROS level. Briefly, seeding of a concentration of $1 \times 10^{4} \mathrm{MCF}-7$ cells per well in DMEM medium supplemented with $10 \%$ FBS was performed in 6 -well plates. Then, cells were treated with different concentrations of compound $4 \mathbf{r}\left(0,2.5,5,10 \mu \mathrm{mol} \cdot \mathrm{L}^{-1}\right.$, respectively) for $24 \mathrm{~h}$. Afterwards, the cells were stained with DCFH-DA $\left(10 \mu \mathrm{mol} \cdot \mathrm{L}^{-1}\right)$ for $30 \mathrm{~min}$ at $37{ }^{\circ} \mathrm{C}$ in the dark after washed twice with PBS. Finally, changes in the intracellular DCF fluorescence were observed by fluorescent microscope (OLYMPUS Co., Japan) with excitation wavelength at $485 \mathrm{~nm}$ and emission wavelength at $538 \mathrm{~nm}$. 4.3.6 Mitochondrial membrane potential $(\Delta \Psi \mathrm{m})$ measurement

A fluorescent probe JC-1 was used to determine the $\Delta \Psi \mathrm{m}$. MCF-7 cells were treated with compound $4 \mathbf{r}(0,2.5$, $5,10 \mu \mathrm{mol} \cdot \mathrm{L}^{-1}$, respectively) and incubated in 6-well plates for $24 \mathrm{~h}$. After treatment, the culture medium was removed, and cells were rinsed twice with PBS and further 
cultured in an equal volume of JC-1 staining solution (3 $\mathrm{mg} / \mathrm{mL}$ ) in the dark for another $20 \mathrm{~min}$. Thereafter, quantitative analysis of red/green fluorescence was detected by confocal microscopy with excitation wavelength at 525/ $490 \mathrm{~nm}$ and emission wavelength at 595/530 nm.

Supporting Information ${ }^{1} \mathrm{H}$ NMR, ${ }^{13} \mathrm{C}$ NMR of compounds $\mathbf{4 a} \sim \mathbf{4 r}, \mathbf{3 a} \sim \mathbf{3 f}$, and $\mathbf{2}$; HRMS spectra of compounds $\mathbf{4 a} \sim \mathbf{4 r}$. The Supporting Information of NMR is available free of charge via the Internet at http://siocjournal.cn/.

\section{References}

[1] Bray, F.; Ferlay, J.; Soerjomataram, I.; Siegel, R. L.; Torre, A. L.; Jemal, A. Ca-Cancer J. Clin. 2018, 68, 394.

[2] Siegel, R. L.; Miller, K. D.; Jemal, A. Ca-Cancer J. Clin. 2020, 70, 7.

[3] Varbanov, H. P.; Kuttler, F.; Banfi, D.; Turcatti, G.; Dyson, P. J. PLoS One 2017, 12, 1

[4] Kinch, M. S. Drug Discovery Today 2014, 19, 1831.

[5] Kim, M.; Park, J.; Sharma, S.; Kim, A.; Park, E.; Kwak, J. H.; Jung, Y. H.; Kim, I. S. Chem. Commun. 2013, 49, 925.

[6] Mirjafary, Z.; Abdoli, M.; Saeidian, H.; Boroon, S.; Kakanejadifard, A. $R S C A d v$. 2015, 5, 79361 .

[7] Vessally, E.; Abdoli, M. J. Iran. Chem. Soc. 2016, 13, 1235.

[8] Zan, N. N.; Wan, F. X.; Wang, S. C.; Zhang, J. H.; Jiang, L. Chin. J. Org. Chem. 2017, 37, 1537 (in Chinese). (冬宁宁, 万福贤, 王士春, 张君辉, 姜林, 有机化学, 2017, 37, 1537.)

[9] Wang, Y.; Zhang, W. D.; Dong, J. Q.; Gao, J. B. Bioorg. Chem. 2020, 95, 103530 .

[10] Chen, L. J.; Wang, X. B.; Tang, X.; Xia, R. J.; Guo, T.; Zhang, C.; Li, X. Y.; Xue, Y. BMC Chem. 2019, 13, 1

[11] Dai, H.; Ge, S. S.; Guo, J.; Chen, S.; Huang, M. L.; Yang, J. Y. Eur. J. Med. Chem. 2018, 143, 1066.

[12] Huang, G.; Dong, J. Y.; Zhang, Q. J.; Meng, Q. Q.; Zhao, H. R.;
Zhu, B. Q.; Li, S. S. Eur. J. Med. Chem. 2019, 165, 160.

[13] Qin, H. L.; Leng, J.; Zhang, C. P.; Jantan, I.; Amjad, M. W.; Naeem, M.; Hussain, M. A.; Nasir, S.; Bukhari, A. J. Med. Chem. 2019, 57, 3549.

[14] Cui, Y. M.; Yasutomi, E.; Otani, Y.; Yoshinaga, T.; Ido, K.; Sawada, K.; Kawahata, M.; Yamaguchi, K.; Ohwada, T. Bioorg. Med. Chem. Lett. 2008, 18, 6386.

[15] Tseng, C. H.; Tzeng, C. C.; Yang, C. L.; Lu, P. J.; Chen, H. L.; Li, H. Y.; Chuang, Y. C.; Yang, C. N.; Chen, Y. L. J. Med. Chem. 2010, 53,6164 .

[16] Silva, A. R.; Grosso, C.; Delerue-Matos, C.; Rocha, J. M. Eur. J. Med. Chem. 2019, 174, 87.

[17] Coseri, S. Mini-Rev. Med. Chem. 2009, 9, 560.

[18] Acid, C.; Reagent, U.; Synthesis, O. Synlett 2009, 683.

[19] Vajpayee, V.; Eun, M.; Lee, S.; Ravikumar, S.; Kim, H.; Ahn, B.; Choi, S.; Ho S.; Chi, K. Tetrahedron 2013, 69, 3511.

[20] Alaoui, S.; Dufies, M.; Driowya, M.; Demange, L.; Bougrin, K. Bioorg. Med. Chem. Lett. 2017, 27, 1989.

[21] Aoki, T.; Hyohdoh, I.; Furuichi, N.; Ozawa, S.; Watanable, F. Bioorg. Med. Chem. Lett. 2013, 23, 6223.

[22] Wang, G. Y.; Liu, X. J.; Li, L. B. Chem. Reag. 2010, 32, 947 (in Chinese).

(王歌云, 刘秀娟, 厉连斌, 化学试剂, 2010, 32, 947.)

[23] Gayet, A.; Bolea C.; Andersson, P. G. Org. Biomol. Chem. 2004, 2, 1887.

[24] Mciteka, L. P.; Lobb, K. A.; Kaye, P. T. ARKIVOC 2016, 2016, 151.

[25] Zhang, J.; Liu, C.; Huang, R. Z.; Chen, H. F.; Liao, Z. X.; Sun, J. Y.; Xia, X. K.; Wang, F. X. PLoS One 2017, 12, 1.

[26] Narayani, S. S.; Saravanan, S.; Ravindran, J.; Ramasamy, M. S.; Chitra, J. Int. J. Biol. Macromol. 2019, 138, 618.

[27] Mills, E. L.; Kelly, B.; O’Neill, L. A. J. Nat. Immunol. 2017, 18, 488.

[28] Zhang, Y. W.; Wang, L. H.; Jia, R. B. Am. J. Cancer. Res. 2020, 10, 1278.

[29] Martinou, J. C.; Youle, R. J. Bone 2011, 21, 92.

[30] He, M.; Yi, Q. Y.; Zhang, W. Y.; Bai, L.; Du, F. New J. Chem. 2019, 2,8566 .

[31] Huang, X. C.; Wang, M.; Pan, Y. M.; Yao, G. Y.; Wang, S. H.; Tian, X. Y.; Qin, J. K.; Zhang, Y. Eur. J. Med. Chem. 2013, 69, 508.

(Fan, Y.) 